\title{
Type I IFN signaling in CD8- DCs impairs Th1-dependent malaria immunity
}

\author{
Ashraful Haque, ${ }^{1}$ Shannon E. Best, ${ }^{1}$ Marcela Montes de Oca, ${ }^{1,2,3}$ Kylie R. James,,3 \\ Anne Ammerdorffer, ${ }^{2}$ Chelsea L. Edwards, ${ }^{1}$ Fabian de Labastida Rivera, ${ }^{2}$ Fiona H. Amante, ${ }^{2}$ \\ Patrick T. Bunn, ${ }^{2}$ Meru Sheel,2 Ismail Sebina, ${ }^{1,3}$ Motoko Koyama, ${ }^{4}$ Antiopi Varelias, ${ }^{4}$ \\ Paul J. Hertzog, ${ }^{5}$ Ulrich Kalinke, ${ }^{6}$ Sin Yee Gun, ${ }^{7}$ Laurent Rénia, ${ }^{7}$ Christiane Ruedl, 8 \\ Kelli P.A. MacDonald, ${ }^{9}$ Geoffrey R. Hill, ${ }^{4}$ and Christian R. Engwerda ${ }^{2}$ \\ ${ }^{1}$ Malaria Immunology Laboratory and 2Immunology and Infection Laboratory, QIMR Berghofer Medical Research Institute, Herston, Brisbane, \\ Queensland, Australia. ${ }^{3}$ University of Queensland, School of Medicine, Mayne Medical School, Herston, Brisbane, Queensland, Australia. \\ ${ }^{4}$ Bone Marrow Transplantation Laboratory, QIMR Berghofer Medical Research Institute, Herston, Brisbane, Queensland, Australia. \\ ${ }^{5}$ Monash Institute of Medical Research, Clayton, Victoria, Australia. ${ }^{6}$ Institute for Experimental Infection Research, TWINCORE, \\ Centre for Experimental and Clinical Infection Research, a joint venture between Helmholtz Centre for Infection Research, Braunschweig, Germany, \\ and Hannover Medical School, Hannover, Germany. ${ }^{7}$ Singapore Immunology Network, Agency for Science, Technology and Research, Singapore. \\ ${ }^{8}$ School of Biological Sciences, Nanyang Technological University, Singapore. ${ }^{9}$ Antigen Presentation Laboratory, \\ QIMR Berghofer Medical Research Institute, Herston, Brisbane, Queensland, Australia.
}

\begin{abstract}
Many pathogens, including viruses, bacteria, and protozoan parasites, suppress cellular immune responses through activation of type I IFN signaling. Recent evidence suggests that immune suppression and susceptibility to the malaria parasite, Plasmodium, is mediated by type I IFN; however, it is unclear how type I IFN suppresses immunity to blood-stage Plasmodium parasites. During experimental severe malaria, $\mathrm{CD}^{+} \mathrm{Th}^{\mathrm{T}}$ cell responses are suppressed, and conventional DC (cDC) function is curtailed through unknown mechanisms. Here, we tested the hypothesis that type I IFN signaling directly impairs cDC function during Plasmodium infection in mice. Using cDC-specific IFNAR1-deficient mice, and mixed BM chimeras, we found that type I IFN signaling directly affects $\mathrm{cDC}$ function, limiting the ability of cDCs to prime IFN- $\gamma$-producing Th1 cells. Although type I IFN signaling modulated all subsets of splenic $\mathrm{cDCs}$, CD8- ${ }^{-}$CDs were especially susceptible, exhibiting reduced phagocytic and Th1-promoting properties in response to type I IFNs. Additionally, rapid and systemic IFN- $\alpha$ production in response to Plasmodium infection required type I IFN signaling in cDCs themselves, revealing their contribution to a feed-forward cytokine-signaling loop. Together, these data suggest abrogation of type I IFN signaling in CD8- splenic cDCs as an approach for enhancing Th1 responses against Plasmodium and other type I IFN-inducing pathogens.
\end{abstract}

\section{Introduction}

Type I IFNs are crucial for protection against viruses but can facilitate survival of many pathogens, such as Listeria $(1,2)$, Mycobacteria (3-7), Staphylococci (8), and Lymphocytic choriomeningitis virus $(9,10)$, as well as protozoan parasites, such as Leishmania (11) and Plasmodium (12). Type I IFN-mediated susceptibility to bacterial infection involves immunomodulatory effects on macrophages, monocytes, and neutrophils via downregulation of cytokine receptor expression, induction of apoptosis, and modulation of recruitment to peripheral tissue sites $(1-6,8)$. In contrast, mechanisms of type I IFN-mediated immune suppression during protozoan parasitic infection remain less studied. A recent report highlighted the potential of Plasmodium DNA to trigger type I IFN responses in vitro (13). Moreover, type I IFN-related genes were transcribed in PBMCs from patients with malaria (13), and SNPs present in the gene encoding the type I IFN receptor chain, IFNAR1, have been linked to resistance to severe malaria $(14,15)$. Recently, we and others demonstrated that type I IFNs mediated susceptibility to Plasmodium using a murine model of severe malaria $(12,13)$. Through the use of BM chimeric mice, we also showed that type I IFNs suppressed IFN- $\gamma$ production by Th 1 cells, not by acting on the

Conflict of interest: The authors have declared that no conflict of interest exists. Citation for this article: J Clin Invest. 2014;124(6):2483-2496. doi:10.1172/JCI70698.
$\mathrm{CD} 4^{+} \mathrm{T}$ cells themselves, but by signaling to an as yet unidentified hematopoietic cell population (12).

In models of severe malaria, splenic conventional DCs (cDCs) rapidly lose ex vivo antigen-presenting capacity and in vivo phagocytic capabilities as pathogen load increases (16-18). This is likely to negatively affect the generation and maintenance of Th cell responses, since $\mathrm{cDCs}$ are responsible for in vivo priming of $\mathrm{CD}^{+}$ $\mathrm{T}$ cells in mild and severe malaria models (19-21). In particular, not only do $\mathrm{CD}^{+}{ }^{+} \mathrm{cDCs}$ fail to cross-present antigens, but MHC class Irestricted and MHC class II-restricted (MHCII-restricted) ex vivo presentation of Plasmodium-expressed antigens by $\mathrm{CD}^{+}$and $\mathrm{CD} 8$ cDCs is also curtailed $(16,17)$. The factors responsible for systemic loss of $\mathrm{cDC}$ function during Plasmodium infection remain unclear.

$\mathrm{CD}^{-}{ }^{-} \mathrm{cDCs}$ have received less attention in recent years compared with $\mathrm{CD}^{+} \mathrm{cDCs}$, which rapidly produce the Th1-inducing cytokine, IL-12, and cross-present exogenous antigen efficiently to $\mathrm{CD}^{+} \mathrm{T}$ cells (reviewed in refs. 22, 23). However, CD8 ${ }^{-} \mathrm{cDCs}$ possess a greater intrinsic capacity for processing antigens onto MHCII molecules than $\mathrm{CD}^{+} \mathrm{cDCs}$ and, therefore, harbor significant potential for priming Th responses (24). It is puzzling, therefore, that CD8 ${ }^{-}$cDCs underperformed substantially in terms of priming Th1 responses compared with $\mathrm{CD}^{+} \mathrm{cDCs}$, when specifically targeted in vivo in the presence of the potent type I IFN-inducing adjuvant, poly I:C $(25,26)$. The reasons for relatively poor CD8 $\mathrm{cDC}$ function in the presence of poly $\mathrm{I}: \mathrm{C}$ adjuvant remain unclear. 

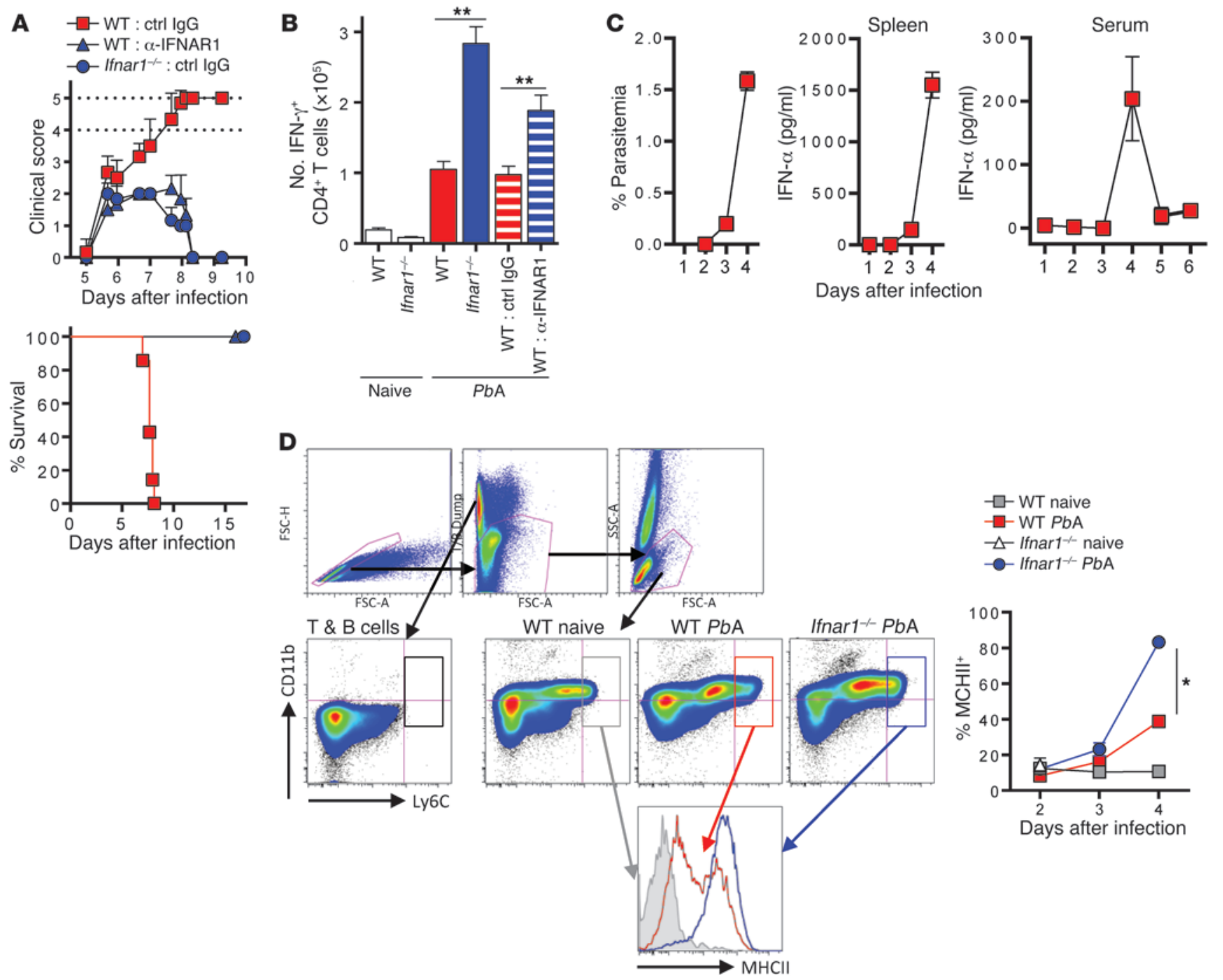

$-\square-$ WT naive

$\neg$ WT PbA

$-\triangle$ Ifnar $1^{-1}$ naive

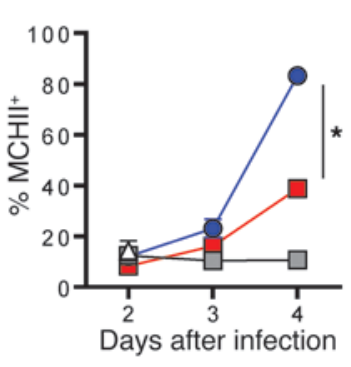

E

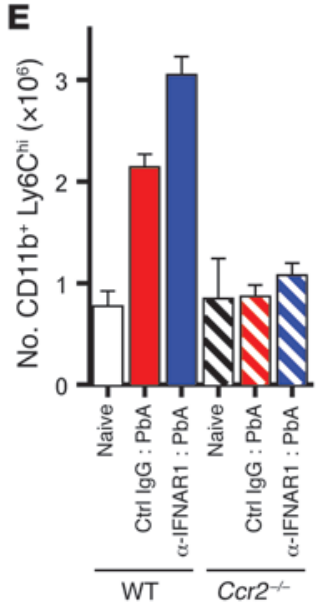

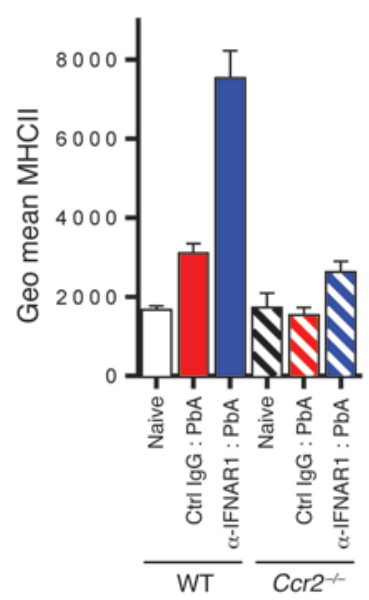

F

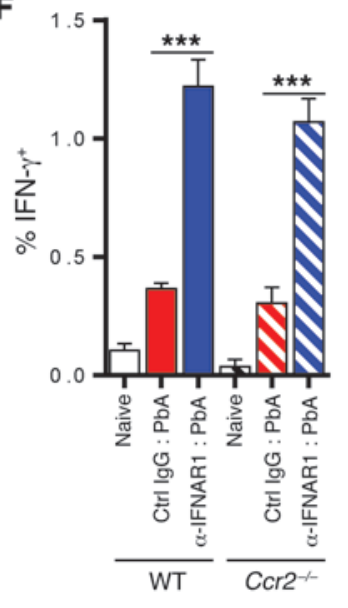

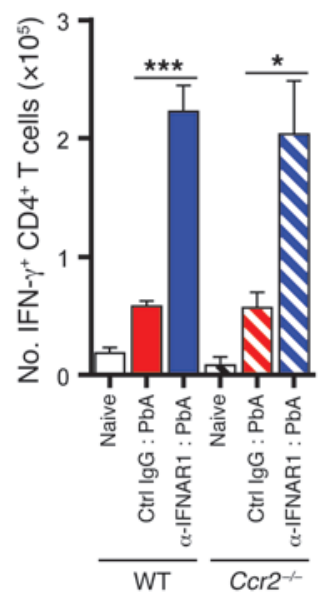




\section{Figure 1}

Type I IFN signaling limits Th1 responses during experimental severe malaria independently of suppressive effects on monocytes. (A) C57BL/6 WT mice $(n=6)$ received $\alpha$-IFNAR1 or control IgG and Ifnar1 $1^{-/}$mice $(n=6)$ received control IgG on days 0,2 , and 4 p.i. with $\mathrm{PbA}$. Mice were assessed for clinical symptoms from day 5 p.i. and for survival (2 independent experiments). Dotted line at clinical score 4 indicates moribund threshold. (B) WT mice $(n=5)$ were infected with $P b A$ and treated with $\alpha$-IFNAR1, control IgG, or left untreated. $P b A$-infected Ifnar1 $1^{-/}$mice $(n=5)$ and uninfected WT and Ifnar $1^{-/-}$ mice $(n=5)$ were also tested. On day 4 p.i., flow cytometric analysis of IFN- $\gamma$ production (without ex vivo stimulation) by splenic CD4+ TCR $\beta^{+}$ cells was performed (2 independent experiments). (C) Time course analysis of parasitemia and IFN- $\alpha$ protein in whole spleen lysates and sera from $\mathrm{PbA}$-infected WT mice (2-5 independent experiments). (D) Gating strategy for Ly6C hi monocytes and MHCIl expression in blood. WT and Ifnar1-/- mice $(n=3-5)$ were infected with $\mathrm{PbA}$ and, at time points indicated, PBMCs were assessed by flow cytometry for cell surface expression of $\mathrm{MHCll}$ on TCR $\beta^{-/ B 220} / \mathrm{CD}_{11} \mathrm{~b}^{+} / \mathrm{Ly} 6 \mathrm{C}^{\text {hi }}$ single cells exhibiting low granularity (2 independent experiments). (E) WT and $\mathrm{Ccr}^{-/-}$mice $(n=5-6)$ were treated with $\alpha$-IFNAR1 or control IgG and infected with $\mathrm{PbA}$. On day 4 p.i., spleens were assessed for numbers of and, cell-surface MHCIl expression by, CD11b+ Ly6Chi monocytes and $(F)$ proportion and absolute numbers of $C D 4^{+} \mathrm{TCR} \beta^{+}$cells producing IFN- $\gamma$ without ex vivo restimulation (2 independent experiments). ${ }^{\star} P<0.05 ;{ }^{* \star} P<0.01 ;{ }^{* *} P<0.001$.

Given separate lines of evidence for type I IFN-mediated disease susceptibility (13), CD8- ${ }^{-}$DC dysfunction (16), and ineffective Th cell responses during severe Plasmodium infection $(12,27)$, we hypothesized that type I IFNs mediate systemic cDC dysfunction, which leads directly to ineffective Th1-mediated immunity. This hypothesis is supported by related data from other inflammatory disease models, including polymicrobial sepsis (28), and allogeneic reactivity after BM transplantation (29). In a murine cecal ligation puncture model of polymicrobial sepsis, type I IFNs impaired CTL responses via a direct effect on cDCs (28), but possible effects on Th cells were not investigated. In murine models of GVHD, type I IFN signaling in hematopoietic cells impaired Th cell responses (29), but the underlying cellular mechanisms were not fully characterized. Here, we used an established mouse model of severe malaria to test the above hypothesis and discovered that type I IFNs directly suppress CD8- ${ }^{-}$DC-mediated generation of parasite-specific IFN- $\gamma$-producing Th 1 cells.

\section{Results}

Type I IFN signaling limits Th1 responses during experimental severe malaria independently of suppressive effects on monocytes. We showed previously, using genetically deficient (Ifnar $1^{-/-}$) mice, that type I IFN signaling in hematopoietic cells suppressed Th1 cell responses and mediated fatal disease symptoms during experimental severe malaria caused by Plasmodium berghei Antwerpen-Kasapa (PbA) infection (12). To confirm that no developmental or immune homeostatic defects in Ifnar $1^{-/-}$mice could account for this phenotype, we first studied WT PbA-infected mice treated with $\alpha$-IFNAR1 blocking antibody. Consistent with genetic IFNAR1 deficiency (12), antibody-mediated blockade of type I IFN signaling completely prevented severe neurological symptoms and morbidity (Figure 1A) and substantially boosted Th1 responses (Figure 1B). Parasitemias remained equivalent between $\alpha$-IFNAR1- and control IgG-treated mice by day 4 after infection (p.i.) (data not shown), consistent with our previous report in Ifnar $1^{-/-}$mice (12). Furthermore, we observed substantial production of IFN- $\alpha$ protein in the spleens and sera during infection, the early kinetics of which mirrored increases in parasitemia (Figure 1C), but whose levels dropped in the sera after day 4 p.i. Together, these data confirm that type I IFN signaling, associated with a pathogen-induced spike of systemic IFN- $\alpha$, suppressed Th1 responses and caused severe, fatal disease during $\mathrm{PbA}$ infection.

We next sought to determine cellular mechanisms by which type I IFN signaling suppressed Th1 responses. Given that hematopoietic type I IFN signaling suppressed antiparasitic Th1 cells indirectly (12), we hypothesized that the APCs responsible for Th1 priming would be directly impaired by type I IFN signaling. Previous reports identify cDC as the major APC responsible for priming Th1 responses to blood-stage Plasmodium, excluding roles for plasmacytoid DCs (pDCs) though not monocyte-derived DCs (moDCs) $(20,21)$. Therefore, we focused our study on cDCs and monocytes. Given an emerging paradigm that type I IFN modulates monocytic responses $(4,30,31)$, we first considered the impact of type I IFN signaling on monocytes during $\mathrm{PbA}$ infection. We noted that the proportion of $\mathrm{CD} 11 \mathrm{~b}^{+}$Ly $6 \mathrm{C}^{\text {hi }}$ monocytes in the blood, and their acquisition of cell surface MHCII (Figure 1D), increased strikingly in PbA-infected Ifnar1 $1^{-/}$mice, compared with that in WT control-infected mice by day 4 p.i. These cells were also more abundant and expressed more cell surface MHCII in the spleens of PbA-infected Ifnar1 $1^{-/-}$mice (data not shown) or WT mice treated with $\alpha$-IFNAR1 (Figure 1E), compared with control-treated, PbA-infected WT mice. This observation was unexpected given that type I IFN promotes, rather than suppresses, monocyte recruitment and activation $(4,30,31)$ and suggested that increased monocyte activation could account for enhanced Th1 responses after type I IFN signaling blockade. However, although monocyte recruitment to the spleen and acquisition of cell surface MHCII was abrogated in $\mathrm{Ccr} 2^{-/-}$mice (Figure 1E), Th1 responses were unaffected compared with those in WT mice, either in the presence or absence of type I IFN signaling (Figure 1F). Importantly, Th1 responses increased in $\mathrm{C} c r 2^{-1-}$ mice treated with $\alpha$-IFNAR1, compared with those in control-treated $\mathrm{Ccr}^{-/-}$mice (Figure 1F). These data show that, although type I IFN signaling suppressed monocyte responses during malaria, this process had no impact on the early development of Th1 cell responses during acute, severe Plasmodium infection.

Type I IFN signaling directly mediates systemic activation of splenic cDCs during PbA infection. Since monocytes played no role in type I IFNmediated suppression of Th1 responses (Figure 1, E and F), we hypothesized that splenic cDCs were the most likely APCs to be impaired by type I IFN signaling $(20,32)$. To test this, we first examined cell surface expression of the costimulatory molecule, CD86, on CD11 $\mathrm{c}^{\text {hi }} \mathrm{MHCII}{ }^{\mathrm{hi}} \mathrm{cDCs}$ (Figure 2A), since it correlates well with their systemic activation and functional impairment during $\mathrm{PbA}$ infection (17). As expected, CD86 upregulation was observed, not during the first 2 days of infection (Figure 2B and ref. 17), but on day 4 p.i. (Figure 2C), when parasitemias had exceeded 1\% (Figure 1C). Importantly, we noted that both IFNAR1 genetic deficiency and $\alpha$-IFNAR1 treatment resulted in 50\% less CD86 upregulation by cDCs (Figure 2C). Similar observations were made in $\mathrm{Ccr} 2^{-/-}$ mice, devoid of splenic monocyte recruitment, when treated with $\alpha$-IFNAR1 or control IgG (data not shown). Together, these data indicate that type I IFN signaling contributed substantially to systemic $\mathrm{cDC}$ activation during $\mathrm{PbA}$ infection.

We next determined whether $\mathrm{CDC}$ systemic activation occurred via direct or indirect type I IFN signaling. To examine this, we first 
A
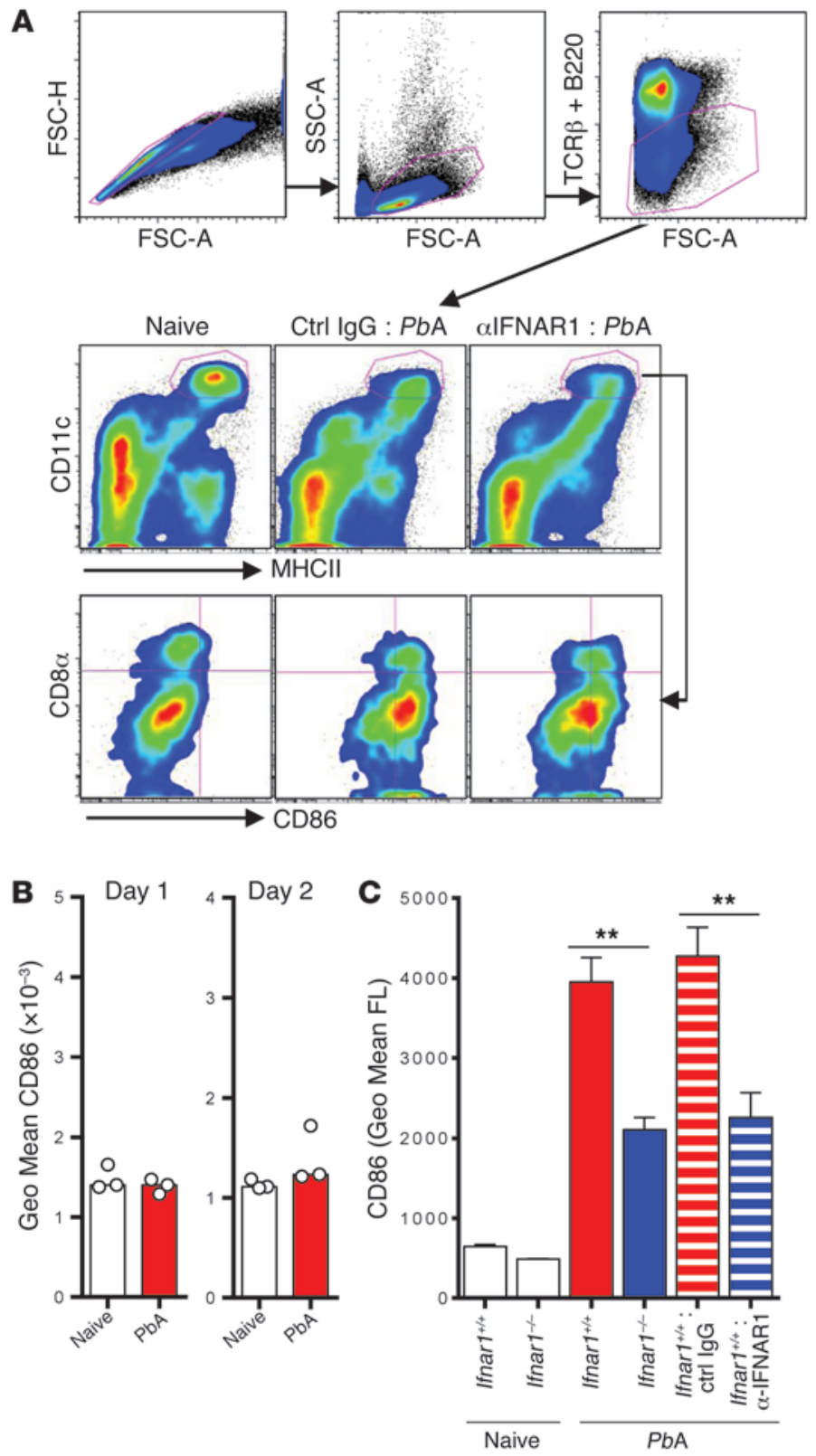

D

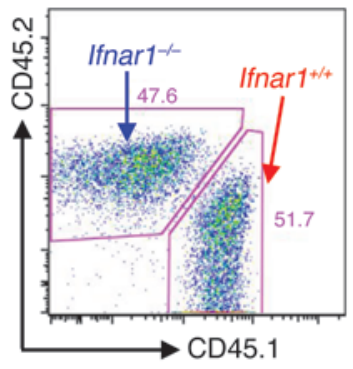

$\mathrm{CD} 8^{+} \mathrm{CDC}$

$\mathrm{CD}^{-} \mathrm{cDC}$
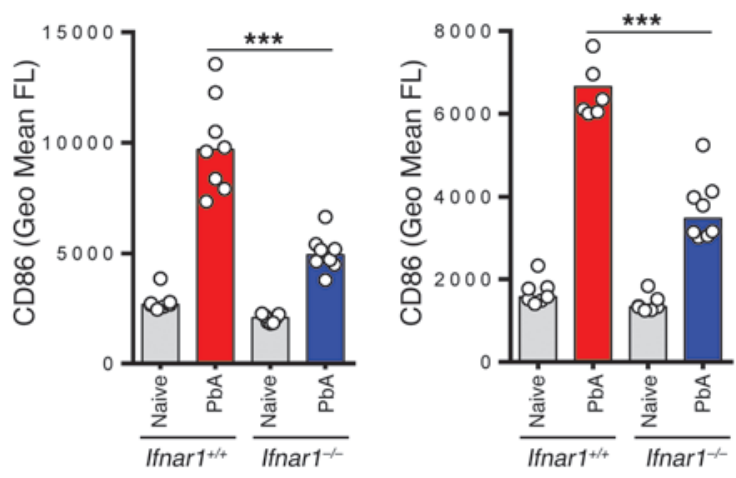

E

$\mathrm{CD}^{+} \quad \mathrm{CD} 8^{-}$

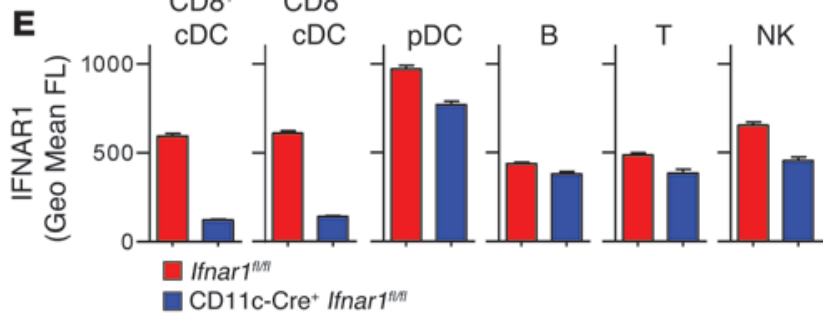

$\mathrm{CD} 8^{+} \mathrm{CDC}$

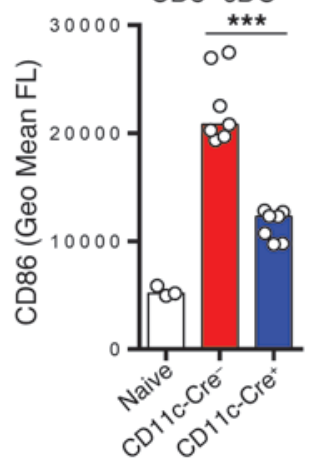

Figure 2

Type I IFN signaling directly mediates systemic activation of splenic $\mathrm{cDCs}$ during PbA infection. (A) Analysis of cell surface CD86 expression by splenic CD8 ${ }^{+}$and CD8- $\mathrm{CDCs}$ (CD11 chiMHCl|hiTCR $\beta{ }^{-}$B220- single cells) from WT mice $(n=5-6) 4$ days p.i. with PbA and after treatment with $\alpha$-IFNAR1 or control IgG (2 independent experiments). (B) Analysis of cell surface CD86 expression by bulk splenic cDCs from WT mice $(n=3)$ on days 1 and 2 p.i. with PbA (experiment performed once). (C) WT mice $(n=5)$ were infected with PbA and treated with $\alpha$-IFNAR1, control IgG, or left untreated. PbA-infected Ifnar1 $1^{-/-}$mice $(n=5)$ and uninfected WT and Ifnar1 $1^{-/-}$mice $(n=5)$ were also assessed. On day 4 p.i., flow cytometric analysis of cell surface CD86 expression by bulk splenic cDCs was performed (2 independent experiments). (D) Flow cytometric assessment of chimerism and cell surface CD86 expression in splenic CD11 $\mathrm{c}^{\mathrm{h}} \mathrm{MHCl|hiTCR} \beta{ }^{-B} 220^{-}$single cells from WT (CD45.1+)//fnar $1^{-/-}$

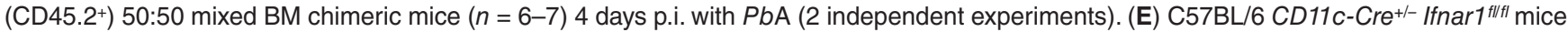

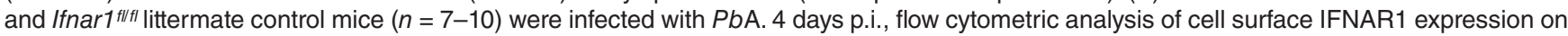

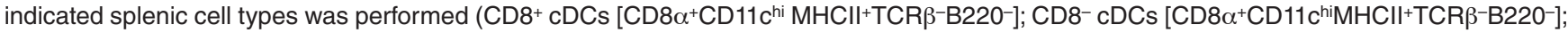

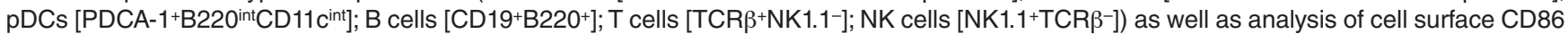
expression by CD8 ${ }^{+}$and CD8 ${ }^{-}$CDCs $\left(2\right.$ independent experiments). ${ }^{* \star} P<0.01 ;{ }^{* \star *} P<0.001$. 
A

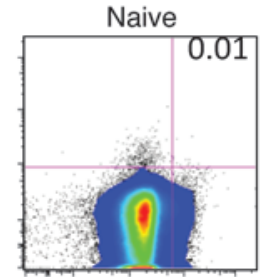

Ifnart flif $^{\text {If }}$

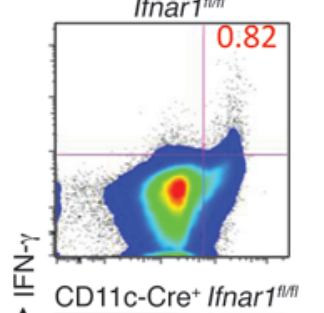

$\begin{array}{r}2,93 \\ \hline\end{array}$

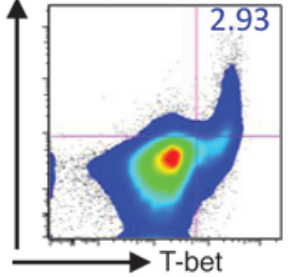

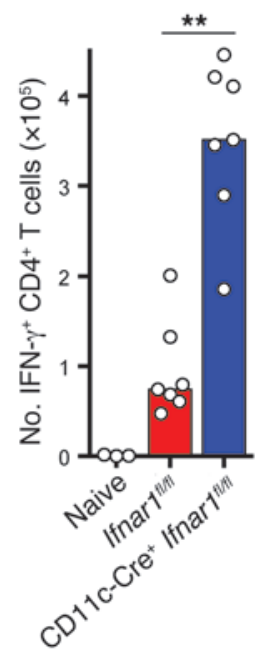
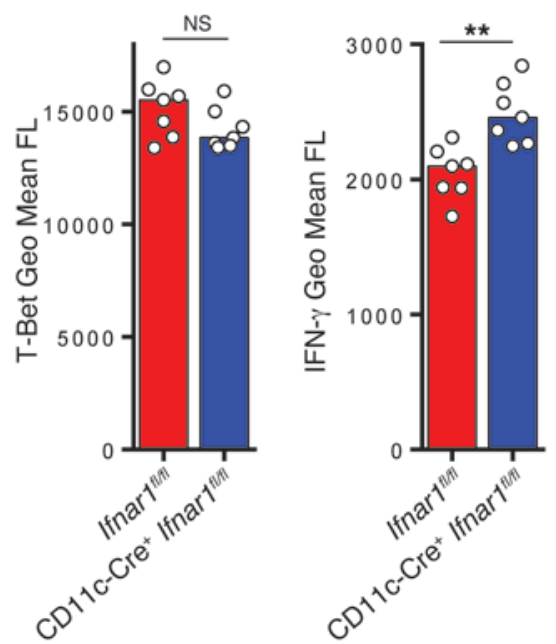

B

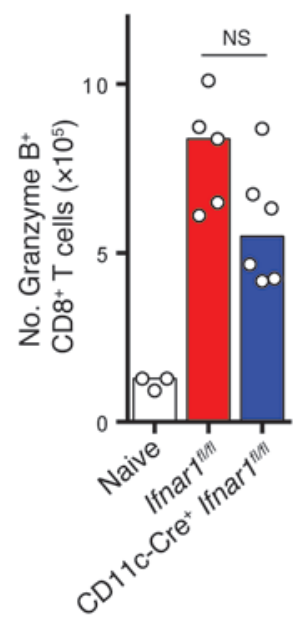

C

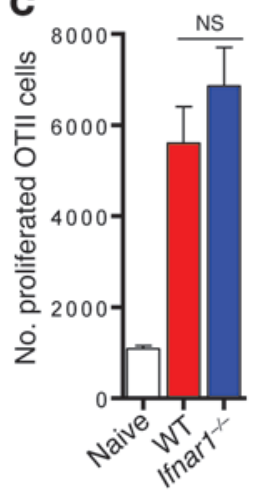

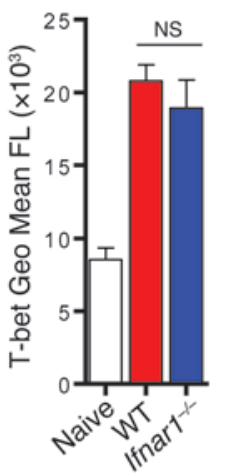

D

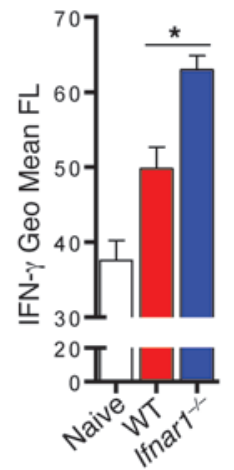

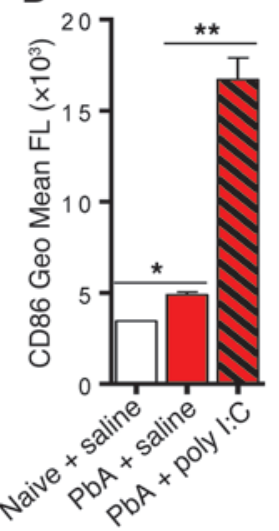

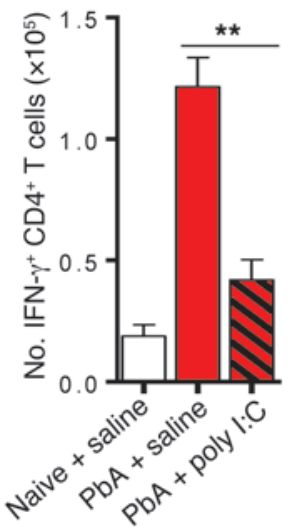

E

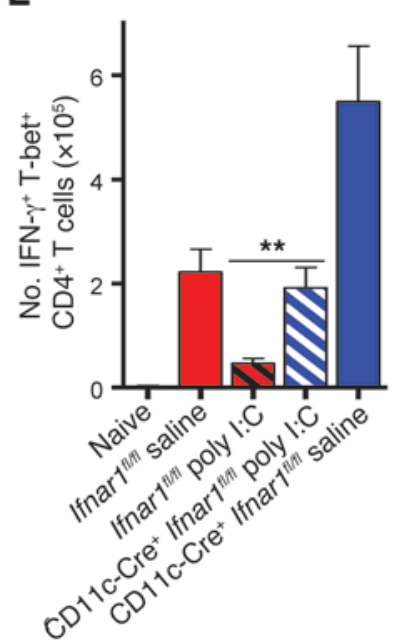

\section{Figure 3}

Type I IFN signaling in cDCs impairs Th1 priming in vivo. (A) FACS analysis of proportions, absolute numbers, and Geo Mean FL intensities for

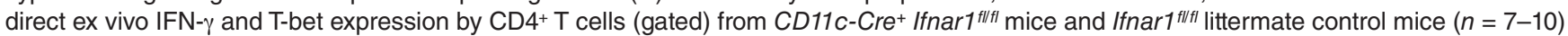
infected with PbA for 4 days (2 independent experiments). (B) FACS analysis of granzyme B expression by splenic CD8 ${ }^{+} \mathrm{T}$ cells from CD11c$\mathrm{Cre}^{+}$Ifnar $1^{\text {fl/fI}}$ mice and Ifnar $1^{\text {fl/fl} l i t t e r m a t e}$ control mice $(n=5)$ infected with $P b A$ for 4 days. (C) WT and Ifnar $1^{-/-}$mice $(n=5-8)$ received $1 \times 10^{5}$ to $2 \times 10^{5}$ CFSE -labeled CD4+CD45.1+ OTII cells 1 day before infection with OTII peptide-expressing PbA. 4 days p.i., splenic OTII cells were assessed for CFSE loss and, subsequently, CFSElo cells were assessed for direct ex vivo T-bet and IFN- $\gamma$ expression (2 independent experiments). (D) WT mice $(n=5)$ were infected with $P b A$ or left uninfected, and treated on day 2 p.i. with poly I:C or control saline. On day 3 p.i., bulk splenic cDCs were assessed by flow cytometry for cell surface CD86 expression, and on day 4 p.i., splenic CD4+TCR $\beta^{+}$single cells were assessed for intracellular IFN- $\gamma$ expression (without ex vivo stimulation) (performed once). (E) Number of splenic Th1 cells in $C D 11 \mathrm{C}-C r \mathrm{e}^{+} / \mathrm{fnar} 1^{\mathrm{fl} / \mathrm{fl}}$ mice and Ifnar ${ }^{f / f f l}$ littermate control mice $(n=5-6)$ infected for 4 days with $P b A$ and treated with poly I:C on day 2 p.i. ${ }^{*} P<0.05$; ${ }^{* *} P<0.01$.

generated mixed BM chimeric mice with congenically marked Ifnar $1^{+/+}$and Ifnar $1^{-/-}$splenic CDCs in equal proportions (Figure 2D). We then assessed CD86 expression by Ifnar $1^{1 /+}$ and Ifnar1 ${ }^{-/}$ splenic cDC subsets in these animals at 4 days p.i. with PbA. Consistent with data from Ifnar $1^{-/-}$or $\alpha$-IFNAR1-treated mice (Figure
2C), CD86 upregulation was approximately $50 \%$ reduced in CD8 ${ }^{+}$ and CD8- Ifnar1 $1^{-/} \mathrm{cDC}$ subsets, compared with corresponding Ifnar $1^{+/+} \mathrm{cDC}$ counterparts (Figure 2D), indicating that direct type I IFN signaling mediated systemic activation of both $\mathrm{cDC}$ subsets. To further establish direct type I IFN signaling as a mechanism for 
systemic activation of cDCs, we used Itgax-Cre ${ }^{+/-}$Ifnar $1^{f / f l}$ (CD11cCre Ifnar $\left.{ }^{f l / f l}\right)$ mice, in which IFNAR1 deficiency was confined to $\mathrm{CD} 11 \mathrm{c}^{\text {hi }}$ cells $(33,34)$. We infected CD11c-Cre Ifnar 1 flffl mice and $\mathrm{Cre}^{-}$Ifnar ${ }^{f l / f l}$ littermate controls with $\mathrm{PbA}$, and monitored IFNAR1 expression and CD86 upregulation on splenic cDCs at day 4 p.i. (Figure $2 \mathrm{E}$ ). We first observed substantial reductions in IFNAR1 expression on $\mathrm{CD}^{+}$and $\mathrm{CD}^{-} \mathrm{CDCs}$ and minor reductions on other immune cells (Figure 2E). Then, consistent with our mixed BM chimeric data (Figure 2D), we once again observed approximately $50 \%$ less upregulation of CD86 by $\mathrm{CD}^{+}$and $\mathrm{CD}^{-}{ }^{-} \mathrm{CDCs}$ in PbA-infected CD11c-Cre Ifnar ${ }^{f l / f l}$ mice, compared with infected Ifnar $1^{f l f l}$ littermate controls (Figure 2E). Together, our data formally identify direct type I IFN signaling as a major cytokine-mediated mechanism for systemic activation of splenic cDCs during $P b A$ infection.

Type I IFN signaling in cDCs impairs their capacity to prime IFN- $\gamma$-producing Th1 cells in vivo. To establish a causal link between type I IFN signaling in $\mathrm{cDCs}$ and Th1 suppression, we next compared Th1 responses in PbA-infected CD11c-Cre Ifnar $1^{f / f l}$ mice and Cre Ifnar $^{\text {fl/fl }}$ littermate controls (Figure 3A). Strikingly, the proportion and absolute number of $\mathrm{CD}^{+} \mathrm{T}$ cells expressing T-bet and IFN- $\gamma$ was substantially increased in CD11c-Cre Ifnar $1^{f / f l}$ mice compared with

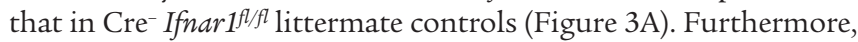
the amount of IFN- $\gamma$, not T-bet, produced on a per cell basis by Th1 cells was significantly enhanced in the absence of type I IFN signaling to $\mathrm{cDCs}$ (Figure $3 \mathrm{~A}$ ). Activation of polyclonal CD8 ${ }^{+} \mathrm{T}$ cells, as assessed by granzyme $B$ upregulation, was not significantly affected (Figure 3B). These data indicated that polyclonal Th1 responses were specifically boosted in magnitude and quality when cDCs were deprived of type I IFN signals. To confirm our findings in parasite-specific $\mathrm{CD} 4^{+} \mathrm{T}$ cells, we next used an established transgenic system $(16,35-37)$, studying adoptively transferred, ovalbumin-specific, CFSE-labeled, OTII CD4 ${ }^{+} \mathrm{T}$ cells after infection with a transgenic $P b$ A strain, $P b T G$, which expresses the OTII peptide (Figure 3C). By day 4 p.i., the number of proliferated OTII cells, and their upregulation of T-bet, was equivalent in the spleens of WT and Ifnar $1^{-/-}$recipient, PbTG-infected mice (Figure 3C). Notably, however, expression of IFN- $\gamma$ was again increased on a per cell basis in proliferated OTII cells from Ifnar $1^{-/-}$mice compared with WT recipient mice. Taken together, our data identify type I IFN signaling in $\mathrm{cDCs}$ as the causal mechanism suppressing IFN- $\gamma$ production by parasite-specific Th1 cells during PbA infection.

To further establish a role for type I IFN signaling in suppressing Th1 responses, we next boosted type I IFN production in PbA-infected mice with a single dose of poly I:C and then studied splenic $\mathrm{cDC}$ and Th1 responses (Figure 3D). Poly I:C treatment triggered potent, systemic IFN- $\alpha$ production (data not shown) and was associated with substantially increased cDC activation the day after treatment and, most importantly, significantly impaired Th1 responses compared with those of saline-treated controls (Figure 3D). Poly I:C-mediated Th1 suppression was partially prevented in CD11c-Cre Ifnar $1^{f l / f l}$ mice compared with that in littermate Ifnar $1^{f / / f l}$ controls (Figure $3 \mathrm{E}$ ), supporting the hypothesis that potent type I IFN signaling in cDCs impairs Th1 priming during PbA infection.

Type I IFN signaling suppresses in vivo Th1 responses independently of $C D 8^{+} C D 207^{+}$splenic $c D C$ s. We next studied possible differential effects of type I IFN signaling on splenic cDC subsets in vivo. It was reported previously that the phagocytic capacity of $\mathrm{cDC}$ subsets was reduced dramatically during severe Plasmodium infection (16). Therefore, we used mixed BM chimeric mice, with equal proportions of congenically marked Ifnar $1^{+/+}$and Ifnar $1^{-/-}$splenic CDCs, to investigate the effect of direct type I IFN signaling on phagocytosis (Figure 4A). Consistent with previous work (16), Ifnar $1^{+/+} \mathrm{CD}^{+}$and $\mathrm{CD}^{-}$cDCs phagocytosed blood-borne, inert fluorescent beads efficiently prior to infection but poorly in mice after infection with $\mathrm{PbA}$ for 4 days. In stark contrast, while Ifnar1 $1^{-/-}$ $\mathrm{CD}^{+}{ }^{\mathrm{cDC}} \mathrm{C}$ remained sensitive to $\mathrm{PbA}$-induced downregulation of phagocytosis, Ifnar $1^{-/-} \mathrm{CD} 8^{-} \mathrm{cDCs}$ retained their full phagocytic potential during infection (Figure 4A). These data provided clear in vivo evidence that direct type I IFN signals specifically impaired the function of splenic CD8- $\mathrm{cDCs}$ but not $\mathrm{CD} 8^{+} \mathrm{cDCs}$.

Therefore, we next hypothesized an important role for CD8cDCs in type I IFN-regulated Th1 priming during PbA infection. To test this, we took advantage of the observation that many splenic $\mathrm{CD}^{+}{ }^{+} \mathrm{cDCs}$ express langerin (CD207), whereas CD8 ${ }^{-} \mathrm{cDCs}$ do not (38). We were thus able to deplete splenic $\mathrm{CD}^{+} \mathrm{CD} 207^{+}$ cDCs by diphtheria toxin (DT) treatment of langerin-DT receptor (langerin-DTR) mice (with control mice receiving saline) (ref. 38 and Figure 4B). $\mathrm{CD}^{+} \mathrm{cDC}$-depleted and control langerin-DTR mice were infected with $P b A$ and administered $\alpha$-IFNAR1 or control IgG. We confirmed substantial, though not complete, depletion of $\mathrm{CD}^{+} \mathrm{cDCs}$ within the $\mathrm{cDC}$ compartment in DT-treated langerin-DTR mice, compared with that in controls (Figure 4B), in accordance with other studies (38). This had no effect on upregulation of CD86 by CD8 ${ }^{-}$cDCs or on the emerging Th1 response (Figure 4B). This is the first in vivo evidence that Th1 priming during blood-stage Plasmodium infection proceeds independently of $\mathrm{CD}^{+} \mathrm{CD}^{2} 27^{+} \mathrm{CDCs}$. Importantly, blockade of type I IFN signals in mice depleted of $\mathrm{CD} 8{ }^{+} \mathrm{CD} 207^{+} \mathrm{cDCs}$ triggered both a reduction in CD86 upregulation by remaining $\mathrm{CD}^{-} \mathrm{cDCs}$ and $\mathrm{a}$ concomitant increase in Th1 responses (Figure 4B). To further test the independence of type I IFN-mediated Th1 suppression from $\mathrm{CD}^{+} \mathrm{cDCs}$, we administered $\alpha$-IFNAR1 or control IgG to PbAinfected Clec9a-DTR mice that had been depleted of CD8 ${ }^{+} \mathrm{cDCs}$ with DT (Figure 4C and ref. 39). Using this second model of CD8 ${ }^{+}$ cDC depletion, we again noted a significant increase in IFN- $\gamma$ production by polyclonal $\mathrm{CD} 4^{+} \mathrm{T}$ cells. Thus, taken together, our in vivo data indicated that $\mathrm{CD}^{-}{ }^{-} \mathrm{cDCs}$ primed Th1 cells more effectively after blockade of type I IFN signaling.

Type I IFN signaling impairs Th1 priming by splenic CD8- $c D C s$. To determine whether blockade of type I IFN signaling improved Th1 priming by $\mathrm{CD} 8^{-} \mathrm{cDCs}$, we first sort-purified splenic $\mathrm{CD}^{-}{ }^{-} \mathrm{cDCs}$, along with $\mathrm{CD}^{+} \mathrm{cDCs}$ for comparison, from $\mathrm{PbA}$-infected WT and Ifnar $1^{-/}$mice (as well as from uninfected WT control mice). Given equivalent cell surface expression of $\mathrm{MHCII}$ by $\mathrm{CD}^{-} \mathrm{cDC}$ from infected WT and Ifnar $1^{-/-}$mice (data not shown), we then loaded WT and Ifnar1 ${ }^{-/-}$cDCs ex vivo with OTII peptide (recognized by ovalbumin-specific CD4+ $4^{+} \mathrm{TCR}$ transgenic T cells) and used these to drive de novo Th development in naive $\mathrm{CD} 4^{+}$OTII T cells in vitro (Figure 5A). Consistent with previous reports, $\mathrm{CD8}^{+} \mathrm{cDCs}$ from all groups stimulated only modest IFN- $\gamma$ production by OTII cells $(16,19)$, reflective of weak Th1 priming. In contrast, while WT CD8- cDCs drove appreciable IFN- $\gamma$ expression by OTII cells, Ifnar1 $1^{-/} \mathrm{CD}^{-} \mathrm{cDC}$ exhibited the greatest capacity to do this, thus indicating a superior capacity to drive Th1 development (Figure $5 \mathrm{~A})$. In addition, we saw no difference in proliferation or Th2 or Th17 cytokine production by OTII cells stimulated with CD8cDCs from either WT or Ifnar $1^{-/}$infected mice (data not shown).

Given that OTII cells do not differentiate readily into T-bet ${ }^{+}$Th1 cells (40), we next chose to stimulate ex vivo an alternative $\mathrm{CD}^{+}$ 
A
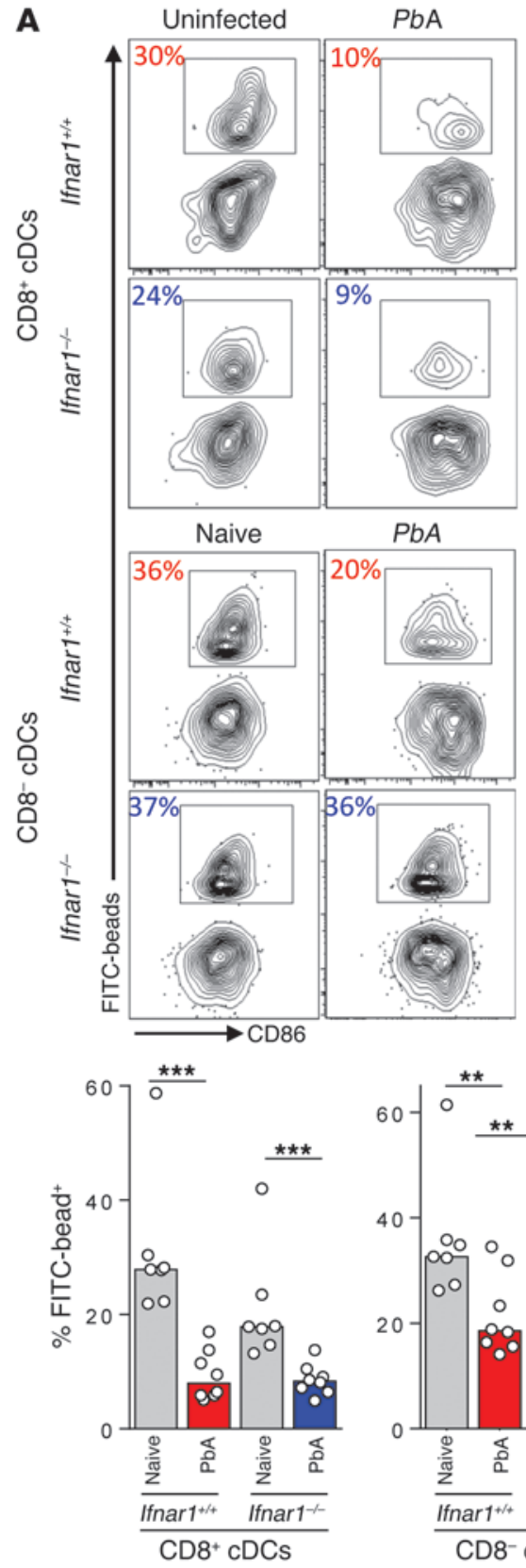

B
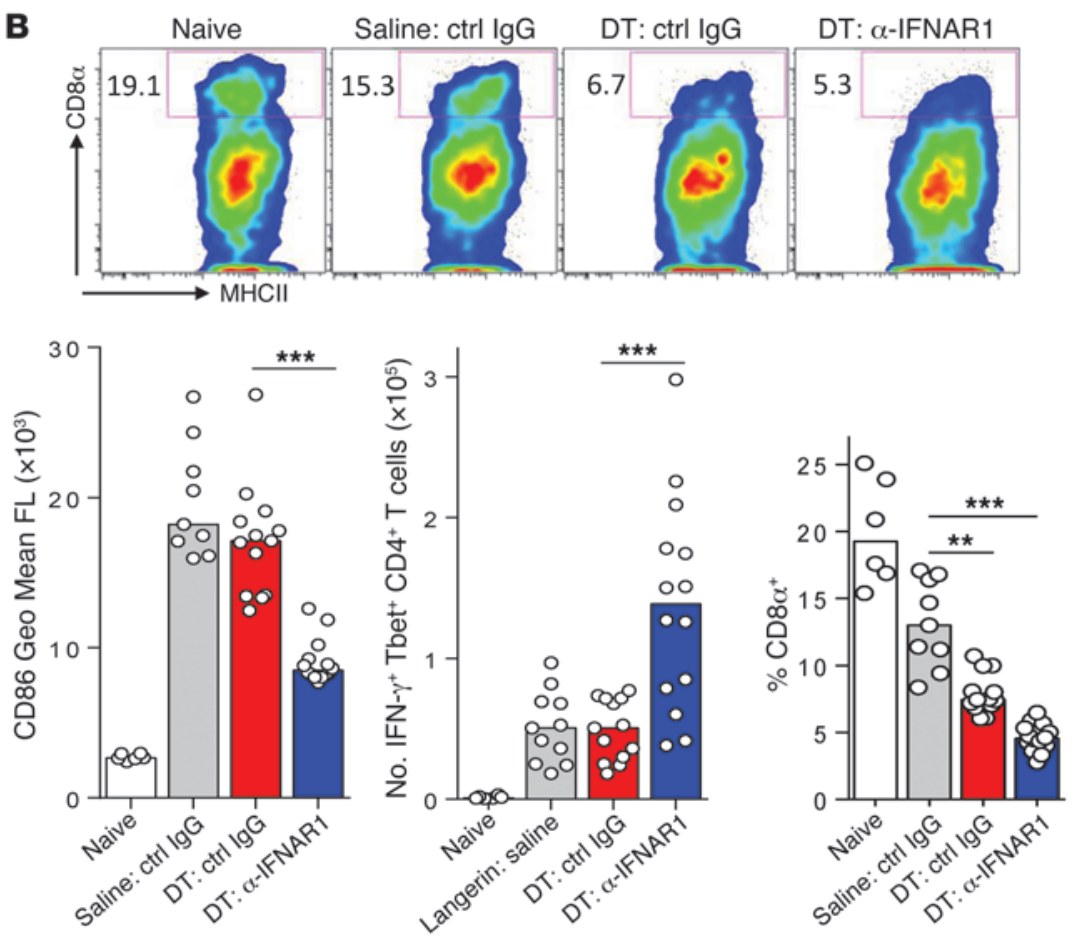

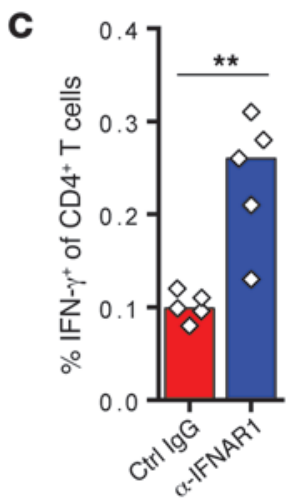

Figure 4

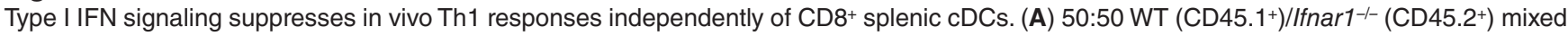
BM chimeric mice $(n=6-8)$, either uninfected or infected 4 days previously with $P b A$, were injected i.v. with FITC ${ }^{+}$beads. 3 hours later, WT

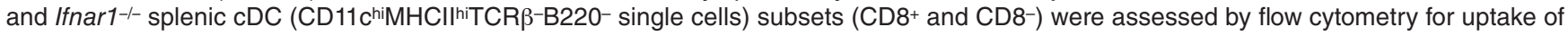
$\mathrm{FITC}^{+}$beads. Percentages indicate proportion of each $\mathrm{CDC}$ population containing at least one bead (2 independent experiments). (B) C57BL/6 langerin-DTR mice were administered DT or control saline, prior to and during $P b A$ infection; $P b A$-infected, DT-treated mice were also treated with $\alpha$-IFNAR1 or control IgG. (A group of mice was also left uninfected and nontreated.) 4 days p.i., flow cytometric analysis of the proportion of

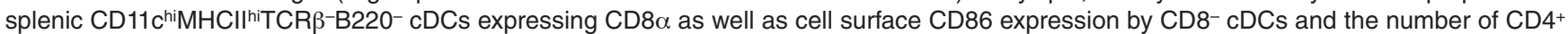
$\mathrm{TCR} \beta^{+}$cells expressing T-bet and IFN- $\gamma$ (without ex vivo stimulation) were assessed (2 independent experiments). (C) The percentage of splenic $\mathrm{CD}^{+} \mathrm{T}$ cells making IFN- $\gamma$ directly ex vivo from Clec9a-DTR (C57BL/6 $\times$ BALB/c F1 background) mice treated with DT, infected for 4 days with $P b A$, and treated with $\alpha$-IFNAR1 or control IgG (experiment performed once). ${ }^{* *} P<0.01 ;{ }^{* \star *} P<0.001$.

T cell from TEa TCR transgenic mice that upregulates T-bet more readily $(40,41)$. TEa cells express a $\mathrm{T}$ cell receptor specific for an I-Ed-derived peptide (E $252-68)$ when presented by MHCII I-A ${ }^{\mathrm{b}}$ molecules (41). When sorted TEa $\mathrm{T}$ cells were cultured with $\mathrm{CD}^{+}$
cDCs from PbA-infected CD11c-Cre Ifnar $1^{f / / f l}$ mice or Ifnar $1^{f / / f l}$ littermates and loaded exogenously with Ea52-68 peptide (Figure $5 \mathrm{~B}$ ), they did not strongly upregulate intracellular T-bet protein expression, which is consistent with the above OTII 

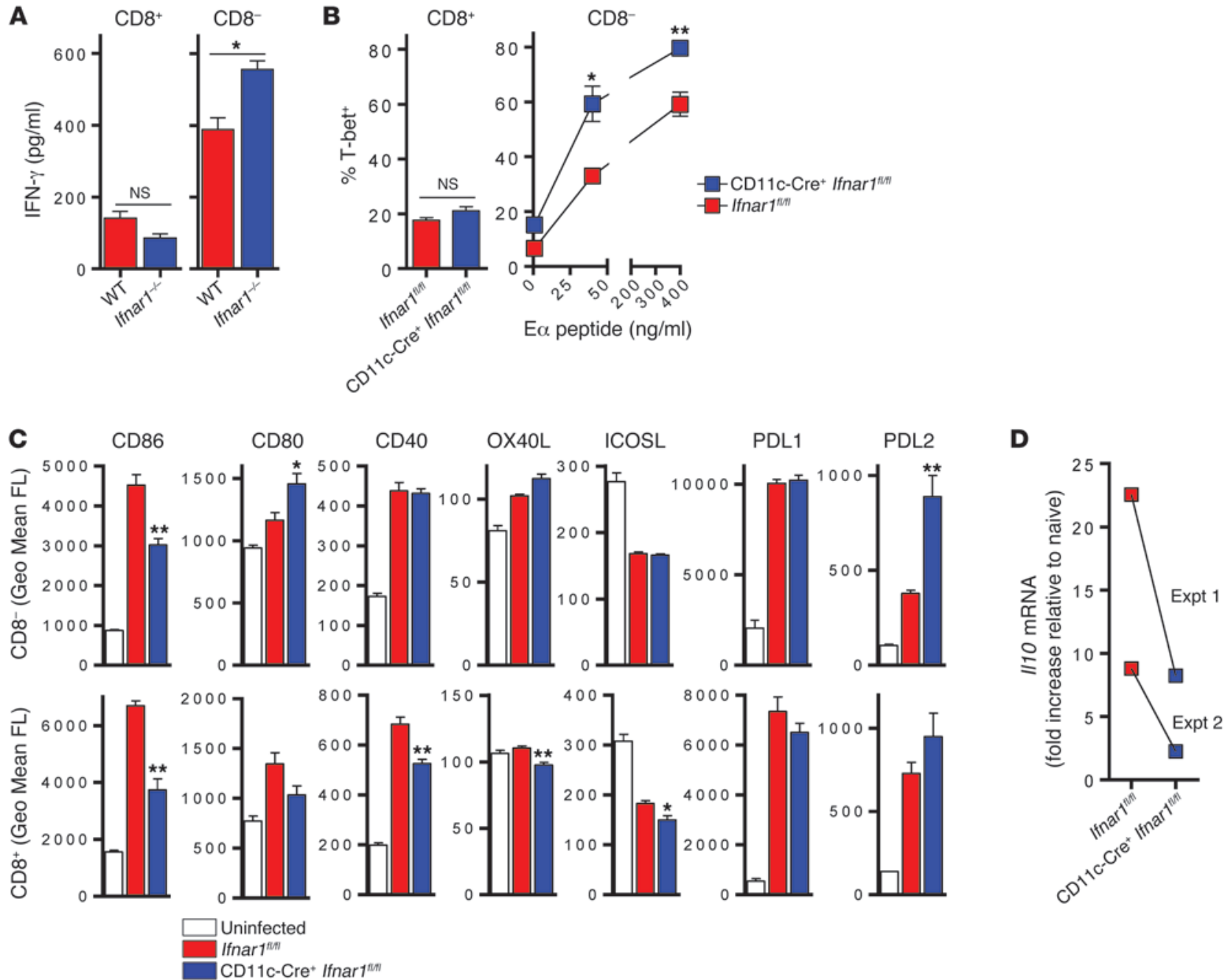

\section{Figure 5}

Type I IFN signaling in cDCs impairs Th1 priming by CD8- cDCs ex vivo. (A) IFN- $\gamma$ assessed in tissue culture supernatants after CD4+ OTII cells (3-6 replicate wells) were stimulated for 4 days with ex vivo OTIl peptide-loaded, cell-sorted, splenic CD8 ${ }^{+}$and CD8 ${ }^{-}$cDCs pooled from WT and Ifnar1-/- mice $(n=5-6)$ infected 4 days previously with $P b A$ (data are mean \pm SEM from a single experiment representative of 2). (B) T-bet expression by CD4+ TCR transgenic TEa T cells (4-5 replicate wells) stimulated for 5 days with ex vivo E $\alpha 52-68$ peptide-loaded, cell-sorted,

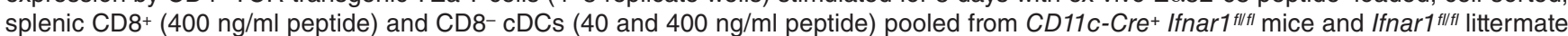
control mice ( $n=6-10)$ infected 4 days previously with PbA (representative of 2 independent experiments). (C) FACS analysis of cell surface

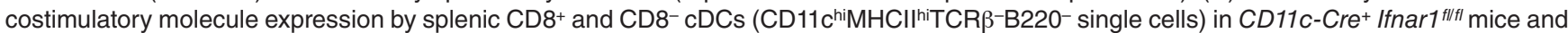

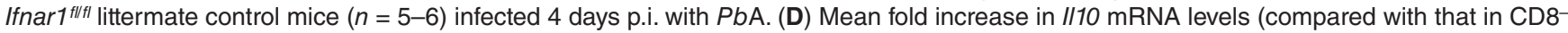

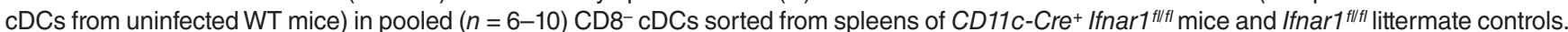
Data from 2 independent experiments presented. ${ }^{*} P<0.05 ;{ }^{* \star} P<0.01$.

data and previous reports $(16,19)$. In contrast, TEa T cells significantly upregulated T-bet when stimulated with CD8- ${ }^{-} \mathrm{CDC}$ from infected Ifnar $1^{f l / f l}$ mice (Figure 5B). Most importantly, however, T-bet upregulation was strongest when stimulated with CD8- cDCs from infected CD11c-Cre Ifnar $1^{f l / f l}$ mice (Figure 5B). Together, our ex vivo antigen presentation experiments indicate that $\mathrm{CD}^{-}{ }^{-} \mathrm{cDCs}$ are specifically impaired from priming Th1 cells via type I IFN signaling to $\mathrm{cDCs}$ in vivo.

We next searched for possible mechanisms to account for the improved Th1-priming capacity of CD8- ${ }^{-}$DCs after type I IFN signaling to cDCs was abrogated. An assessment of B7 family costimulatory molecule expression by $\mathrm{CD}^{+}$and $\mathrm{CD}^{-} \mathrm{cDC}$ from PbA-infected CD11c-Cre Ifnar $1^{f / f l}$ mice and Ifnar $1^{f l / f l}$ littermates revealed that, in addition to reduced CD86 upregulation in both cDC subsets, there were modest effects on many molecules, including CD80, CD40, OX40L, and ICOSL, which appeared mostly on $\mathrm{CD}^{+} \mathrm{cDCs}$ (Figure 5C). Of particular interest, however, was a specific 2- to 3-fold increase in PDL2 expression on $\mathrm{CD}^{-}{ }^{-} \mathrm{cDCs}$, but not $\mathrm{CD}^{+} \mathrm{cDCs}$, in the absence of $\mathrm{CDC}$-specific type I IFN signaling (Figure $5 \mathrm{C}$ ), an observation also seen on $\mathrm{CD}^{-} \mathrm{cDC}$ in $\mathrm{CD}^{+}$ cDC-depleted, infected Clec9a-DTR mice treated with $\alpha$-IFNAR1 compared with control IgG (data not shown). Furthermore, we noted that upregulation of $I l 10$ mRNA by CD8 ${ }^{-}$cDCs was reduced in CD11c-Cre Ifnar $1^{f / f l}$ mice compared with that in controls (Figure 5D), while we found no evidence for increased Il12p40 or $p 35$ mRNA levels (data not shown). Together these data indicate that 
A
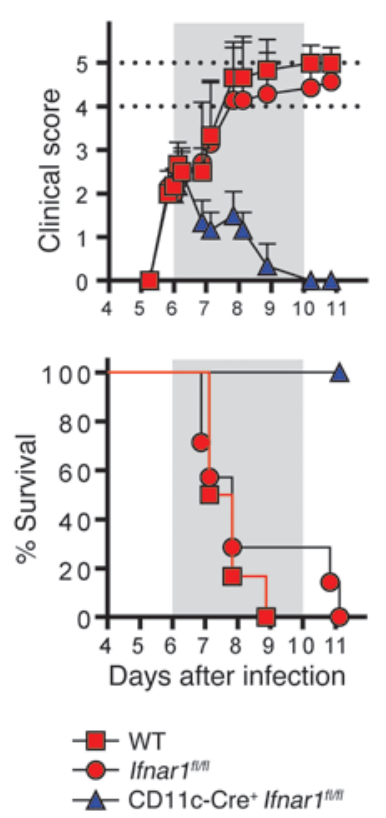

B
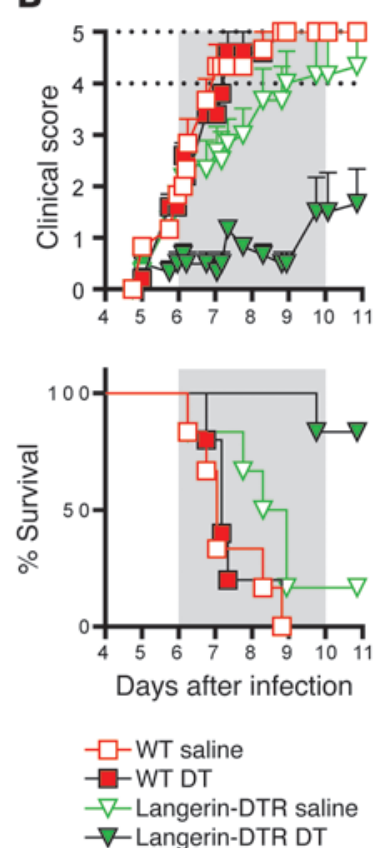

C
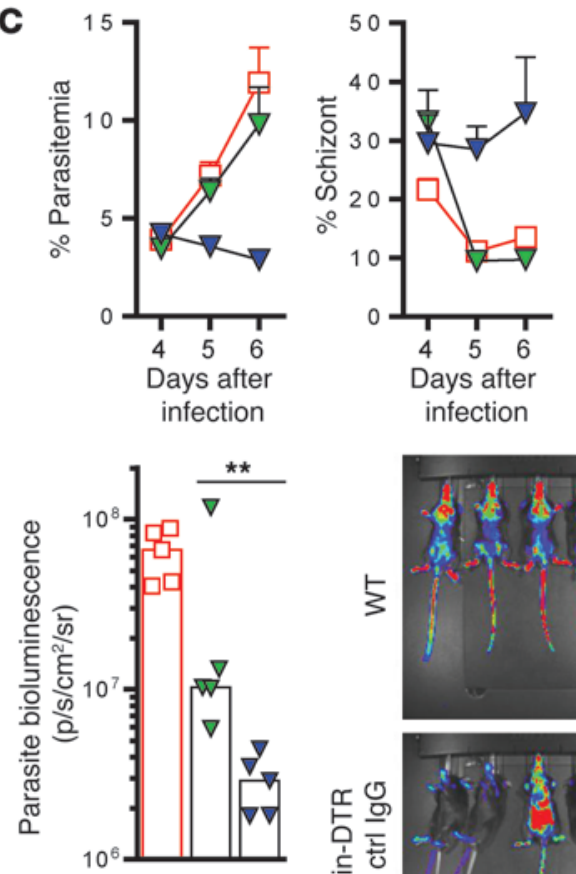
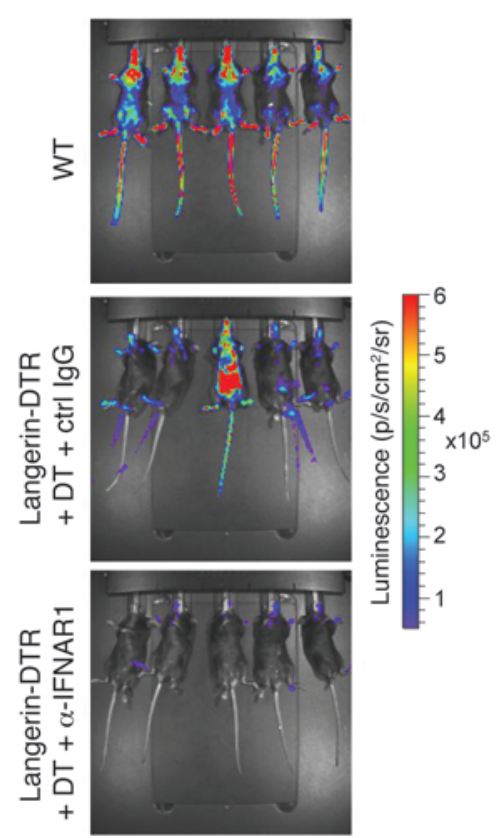

\section{Figure 6}

Type I IFN signaling in cDCs mediates disease susceptibility and impairs parasite control during PbA infection. (A) $C D 11 c-C r e^{+}$Ifnar $1^{f / f l}$ mice and Ifnar $1^{f / f f l}$ littermate controls $(n=8)$ and WT mice were infected with PbA and scored for clinical symptoms and percent survival. Gray area indicates time frame for neurological symptoms in WT mice. Dotted line at clinical score 4 indicates moribund threshold. (B) Langerin-DTR and WT mice $(n=6)$ were treated with DT or saline prior to and during infection with PbA. Mice were monitored for clinical scores and percent survival. Gray area indicates time frame for neurological symptoms in WT saline-treated group. Dotted line at clinical score 4 indicates moribund threshold. (C) Parasitemias and the proportion being mature-stage schizonts in peripheral blood, and whole body luciferase-expressing parasite-derived bioluminescence (day 6 p.i.) in langerin-DTR mice $(n=5)$, given DT prior to and throughout infection with $P b A$ and treated with $\alpha$-IFNAR1 or Ctrl IgG (compared with PbA-infected WT mice). ${ }^{*} P<0.01$.

improved function of CD8- cDCs, as a result of type I IFN signaling blockade in cDCs, was associated with increased PDL2 expression and reduced Il10 mRNA levels.

Type I IFN signaling in cDCs mediates disease susceptibility and impairs parasite control during PbA infection. We next determined the impact of preventing type I IFN signaling to $\mathrm{CDCs}$ on disease outcome during lethal PbA infection. First, we observed that CD11c-Cre Ifnar $f^{f l / f l}$ mice were completely protected from neurological symptoms and death, compared with Ifnar $1^{f l / f l}$ littermates or WT control mice (Figure 6A), thus indicating an absolute requirement for type I IFN signaling in cDCs for disease susceptibility in this model of severe malaria. To determine whether parasite control was improved by blocking type I IFN signaling in the absence of $\mathrm{CD}^{+} \mathrm{cDCs}$, we first confirmed a recent report that mice depleted of $\mathrm{CD} 8^{+} \mathrm{CD} 207^{+}$ $\mathrm{cDCs}$ were protected from lethal neurological disease during $\mathrm{PbA}$ infection (ref. 42 and Figure 6B). Consistent with this report, we found that langerin-DTR mice were resistant to disease when treated with DT but not saline. WT control mice given either DT or saline remained equally susceptible to lethal disease (Figure 6B).

We next determined whether type I IFN blockade could improve

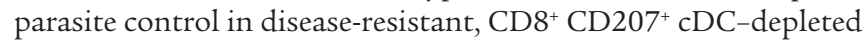
mice (Figure 6C). Strikingly, we observed that DT-treated, langerinDTR mice given $\alpha$-IFNAR1 exhibited much improved control of peripheral blood parasitemia compared with control IgG-treated counterparts (Figure 6C). Moreover, given our recent data that large proportions of mature-stage parasites in the bloodstream are indicative of a slow-growing parasite population (43), we also saw evidence of slowed parasite population growth as a result of $\alpha$-IFNAR1 treatment (Figure 6C). Finally, we observed nearly a 10 -fold reduction in whole body parasite burdens in $\alpha$-IFNAR1- 

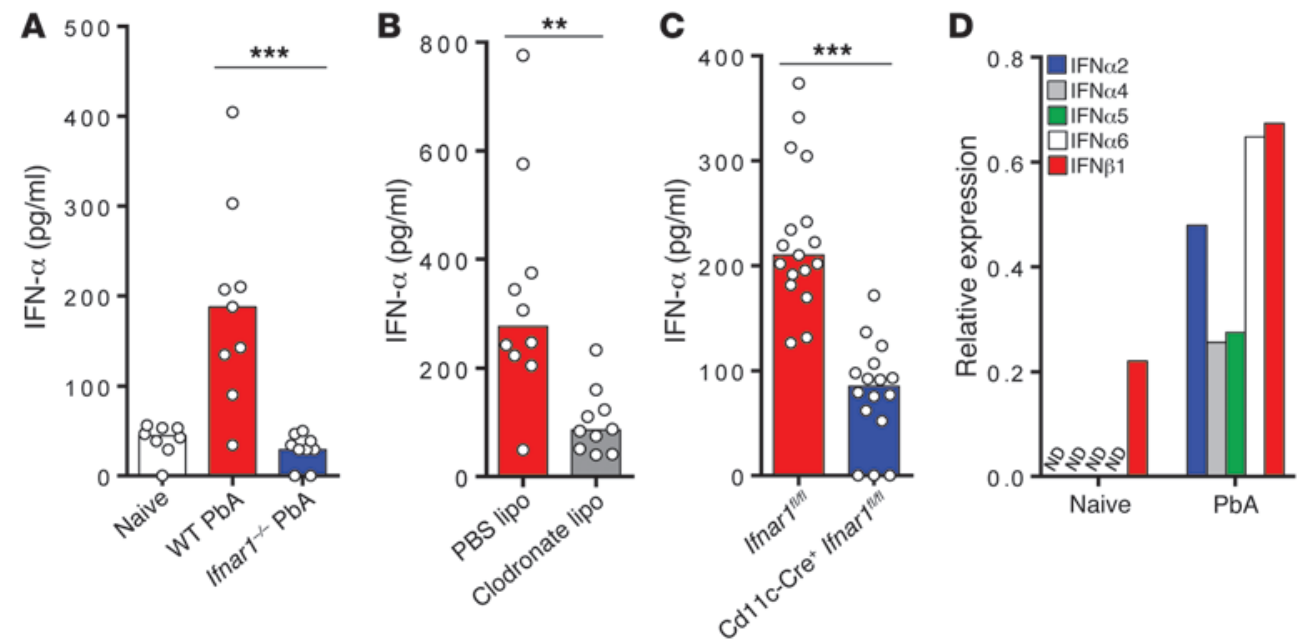

Figure 7

Splenic IFN- $\alpha$ production depends on feed-forward, type I IFN signaling in cDCs. Assessment of serum IFN- $\alpha$ levels on day 4 p.i. in PbA-infected (A) WT and Ifnar $1^{-1-}$ mice (pooled from 2 independent experiments), (B) mice treated 1 day prior to infection with clodronate liposomes or control PBS liposomes (pooled

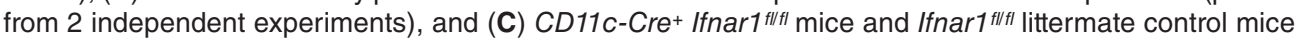
(pooled from 2 independent experiments). (D) IFN- $\alpha / \beta$ gene expression by qPCR in sorted splenic CD8cDCs from pooled WT mice $(n=5) 3$ days p.i. with $P b A$ or naive controls. Results indicate expression relative to sorted splenic pDCs from WT infected mice on day 3 p.i. ND, not detected. ${ }^{* \star} P<0.01 ;{ }^{* \star *} P<0.001$.

treated mice compared with that in control IgG-treated, CD8 ${ }^{+}$ $\mathrm{CD} 207^{+} \mathrm{cDC}$-depleted mice (Figure 6C). Together, our data are consistent with type I IFN signaling to $\mathrm{CD}^{-}{ }^{-} \mathrm{cDCs}$ impairing parasite control and thus contributing to lethal disease during $\mathrm{PbA}$ infection. cDCs participate in a feed-forward loop that maximizes rapid type I IFN production. Our previous data suggested that $\mathrm{pDCs}$ are unlikely to be the sole source of suppressive type I IFN during PbA infection (20). In contrast, since cDCs prime Plasmodium-specific $\mathrm{CD}^{+} \mathrm{T}$ cell responses, express type I IFN genes (20), and, as shown here, are themselves targets of type I IFN signaling, we hypothesized that cDCs operated in a cytokine-signaling loop, in which they not only responded to, but were also required for, the production of type I IFNs. To test this, we first measured serum IFN- $\alpha$ levels in PbAinfected Ifnar1 $1^{-/}$mice (Figure 7A) and WT mice depleted of phagocytic cells by clodronate liposome treatment (Figure 7B). In both situations, serum IFN- $\alpha$ levels were greatly reduced, demonstrating the existence of an IFNAR1-dependent signaling loop requiring phagocytic cells. We also observed substantially lower levels of serum IFN- $\alpha$ at day 4 p.i. in CD11c-Cre Ifnar $1^{f l / f l}$ mice, compared with those in infected Ifnar ${ }^{f l / f l}$ littermate controls (Figure 7C). Finally, given that CD8 ${ }^{-}$cDCs were major targets of type I IFN-mediated suppression, we next determined whether these cells in particular might be a source of type I IFNs. By day 3 p.i., we noted marked upregulation of several IFN- $\alpha / \beta$ mRNAs, not only in pDCs, as expected (20), but also in CD8 ${ }^{-}$cDCs (Figure 7D). Taken together, our data suggest that during $\mathrm{PbA}$ infection, a feedforward loop comprised of IFN- $\alpha / \beta$ production by $C D 8^{-} \mathrm{cDCs}$ and autocrine or paracrine type I IFN signaling in CD8- ${ }^{-}$DCs contributes to the impairment of Th1 priming.

\section{Discussion}

In this study, we show that type I IFN signaling directly modulates the function of CD8- ${ }^{-}$DCs during severe blood-stage Plasmodium
Several groups have established that blood-stage Plasmodium infection triggers profound systemic $\mathrm{cDC}$ activation and dysfunction using murine and human experimental systems (16-18, 44-47). However, the host-derived factors that contribute to this process have remained unclear, although one report suggested that systemic TNF mediates CDC paralysis (44). Nevertheless, our data clearly demonstrate a significant role for type I IFN signaling in functional impairment of CD8- cDCs.

$\mathrm{CD}^{+} \mathrm{cDCs}$ have received greater attention than $\mathrm{CD}^{-} \mathrm{cDCs}$ in many studies in recent years, particularly for their capacity to efficiently cross-present exogenous antigen to $\mathrm{CD}^{+} \mathrm{T}$ cells and produce IL-12 rapidly (reviewed in refs. 22, 23). Moreover, recent studies highlight the unique ability of $\mathrm{CD} 8^{+} \mathrm{CDCs}$ to drive immune-pathogenic $\mathrm{CD}^{+} \mathrm{T}$ cell responses during $\mathrm{PbA}$ infection $(39,42)$. However, elegant in vivo studies, which targeted antigenic proteins to splenic cDC subsets, demonstrated that $\mathrm{CD}^{-}{ }^{-} \mathrm{CDCs}$ possess a greater intrinsic capacity for processing antigens onto MHCII than $\mathrm{CD}^{+}$cDCs (24). However, in subsequent studies, in which Th1 development was assessed after similar in vivo targeting of cDC subsets in the presence of poly I:C, CD8- ${ }^{-}$DCs substantially underperformed compared with $\mathrm{CD}^{+} \mathrm{CDCs}(25,26)$. Indeed, we also observed that poly I:C treatment reduces Th1 responses during Plasmodium infection (Figure 3, D and E). Our data provide an explanation for such suboptimal $\mathrm{CD}^{-} \mathrm{cDC}$ function: while these cells express the appropriate intracellular machinery to efficiently process onto MHCII, excessive type I IFN responses functionally paralyze these cells and impair their capacity to drive Th1 development. Our work supports a role for CD8 ${ }^{-}$cDCs in driving Th cell differentiation in vivo (48-50) but, most importantly, shows that under conditions in which substantial type I IFN is produced, CD8cDCs are prevented from priming strong Th1 responses.

In the model of acute, severe malaria used in this study, enhanced moDC responses did not appear to improve early Th1 develop- 
ment. These data are entirely consistent with previous studies in which CCR2-expressing cells played little or no role during the first week of infection in controlling blood-stage Plasmodium infection $(32,51)$. Nevertheless, work using other malaria models and pathogens suggests that enhancing monocyte and moDC activity via type I IFN blockade could play a beneficial role in persistent and chronic Plasmodium infections, via direct killing of parasitized rbc, and maintenance of Th1 immunity (51-53).

During viral infection, type I IFNs are produced by pDCs in a TLR9-dependent manner (reviewed in ref. 54). However, while these cells are activated during Plasmodium infection, they do not play a major role in immune cell activation or disease outcome $(20,21)$. Data from nonviral infection models indicate that various macrophage populations in the spleen are major sources of type I IFNs $(28,55,56)$. Our data are consistent with this notion and also propose that $\mathrm{cDCs}$ themselves could produce and respond to type I IFNs in an autocrine or paracrine manner (57). Thus, we propose a model in which appropriately positioned phagocytic cells in the spleen, such as macrophages and DCs located in the marginal zone, interact with parasitized $\mathrm{rbc}$ and produce type I IFNs. These cytokines then restrict PDL2 expression, increase Il10 mRNA levels, and suppress phagocytosis in all splenic CD8- $\mathrm{cDCs}$, regardless of whether they have taken up parasites or not. Ultimately, this process restricts IFN- $\gamma$ production by T-bet ${ }^{+}$Th 1 cells.

Our data demonstrated that type I IFN signaling in CD8- $\mathrm{cDCs}$ induced a costimulatory phenotype that was suboptimal for Th1 priming and was associated with higher CD86/CD80 ratios and reduced PDL2 expression. The functional consequences of modulating CD86/CD80 expression levels remain unclear at present. However, given different binding affinities of CD80 and CD86 for CD28 and CTLA-4 (58-60), it is possible that changes in the relative expression of these molecules by $\mathrm{CD}^{-} \mathrm{cDCs}$ will have functional consequences for Th1 priming. The functional consequences of increased PDL2 levels on CD8 ${ }^{-}$cDCs for Th1 priming also remain unstudied at present. However, given that PD1/PDL1 (but not PD1/PDL2) interactions potently suppress Th1 responses during experimental malaria $(61,62)$, and since PDL2 and PDL1 exhibit similar $\mathrm{K}_{\mathrm{d}}$ values for PD1 (63), we hypothesize that PDL2 disrupts the suppressive interactions between PD1 on Th cells and PDL1 on CD8 ${ }^{-}$cDCs. In addition to effects on costimulatory molecule expression, we observed a substantial decrease in Il10 mRNA expression in CD8- ${ }^{-}$DCs deprived of type I IFN signals. Although we could not find evidence of increased $I l 12 p 40$ or $p 35$ mRNA expression in these cells (data not shown), it is possible that reduced $\mathrm{cDC}$ expression of the suppressive cytokine IL-10 might lead directly or indirectly to effects on Th1 cells. Finally, we also observed that type I IFN signaling in $\mathrm{CD}^{-} \mathrm{cDCs}$ suppressed phagocytosis. It is therefore possible that, in addition to effects on costimulatory molecule expression and IL-10, a sustained ability to take up parasitized red blood cells (prbc) might also contribute partially to an improved capacity for Th1 priming in $\mathrm{CD}^{-} \mathrm{cDCs}$. This aspect of $\mathrm{CD}^{-} \mathrm{cDC}$ function remains to be addressed fully.

In considering suppression of CD8- ${ }^{-}$DCs by type I IFN signaling more generally, it is likely that this process is beneficial in some instances for the prevention or amelioration of Th cell-mediated immune pathology, for example, in multiple sclerosis models $(64,65)$. Nevertheless, during the coevolution of Plasmodium and humans, it is possible that this mechanism permitted both the prevention of host immune pathology and the provision to the parasite of an opportunity to establish itself within the host. Given a report that AT-rich DNA motifs in the Plasmodium falciparum genome trigger type I IFN production, it is tempting to hypothesize that Plasmodium, via its DNA, triggers type I IFN responses during the blood stage of infection to facilitate its own survival (13).

The functional impairment of CD8 ${ }^{-}$cDCs by direct type I IFN signaling during blood-stage Plasmodium infection suggests that blockade of the IFNAR1/2 receptor complex on these cells could improve naturally acquired and vaccine-mediated protection against malaria. There is currently no licensed vaccine against Plasmodium, and the current best candidate was recently shown to provide only modest, short-lived, protection in phase III clinical trials in Africa (66). Given that humoral and cellular immunity to Plasmodium is likely to hinge upon effective $\mathrm{CD}^{+} \mathrm{T}$ cell responses (67), these could be boosted by a vaccine strategy acting on the appropriate $\mathrm{cDC}$ population. Moreover, it is possible that people living in endemic regions, who experience repeated Plasmodium infections, may benefit from immune therapies aimed at transiently blocking suppressive type I IFN signals to specific $\mathrm{CDC}$ subsets. The benefit of such a highly targeted approach may be to improve protection against severe malaria without excessively compromising cytotoxic T cell-mediated immunity to viral pathogens. Finally, the question of whether viral vectors, which drive strong type I IFN responses, are indeed appropriate formulations for Th1-dependent vaccines should be considered carefully $(68,69)$. Further work is required to determine the affect of type I IFN signaling on vaccination and immune therapy against Plasmodium infection.

\section{Methods}

Mice, parasites, and infections. C57BL/ 6 and congenic CD $45.1^{+} \mathrm{C} 57 \mathrm{BL} / 6$ mice (female, 6 to 10 weeks of age) were purchased from Australian Resource Centre (Canning Vale) and maintained under conventional conditions. C57BL/6 Ifnar1 $1^{-/-}$mice $(70,71)$, langerin-DTR mice (38), Itgax $-\mathrm{Cre}^{+/-}$ Ifnar $1^{f / f l}$ mice (33), Ifnar $1^{f / / l}$ mice (72), Ccr2 $2^{-/-}$mice (73), congenic (CD 45.1 $1^{+}$) OTII mice (74), and TEa $\times$ Rag $1^{-/-}$mice (41) were all maintained in-house at QIMR Berghofer Medical Research Institute. Clec9a-DTR mice (39) were housed and used according to local animal ethics requirements at Nanyang Technological University.

BM chimeric mice were prepared by i.v. injecting $5 \times 10^{6}$ fresh syngeneic BM cells (from femurs of CD45.1 WT and CD $45.2^{+}$Ifnar1 $1^{-1-}$ mice, mixed at a 50:50 ratio) into lethally irradiated (11 Gy [ ${ }^{137} \mathrm{Cs}$ source]) CD $45.1^{+}$ C57BL/ 6 recipient mice and treating them for 14 days with antibiotics in drinking water (neomycin sulphate, $1 \mathrm{~g} / 1$; Sigma-Aldrich). Engraftment in mixed BM chimeras was assessed after 8 to 12 weeks by flow cytometry. Chimeras were infected 12 weeks after BM transplantation.

$P b A$ parasites were used after 1 in vivo passage in WT C57BL/6 mice. Transgenic $P b A$ (clone 231c1l) constitutively expressing luciferase and GFP from the EF1- $\alpha$ promoter (PbA-luc) was used for all $P b A$ experiments, unless stated otherwise $(35,75)$. A transgenic PbA strain (PbTG) expressing model $\mathrm{T}$ cell epitopes, including the OTII epitope and control strains $(\mathrm{Pb} \mathrm{G})$, was obtained from William R. Heath (University of Melbourne, Melbourne, Australia) and maintained and used as previously reported (37). Mice were infected i.v. with $10^{5} \mathrm{prbc}$, and blood parasitemia was measured in Diff-Quick-stained (Lab Aids) thin blood smears obtained from tail bleeds. Alternatively, an adapted version of a previously established flow cytometric method (76-78) was used to measure parasitemia more rapidly. Briefly, a single drop of blood, from a tail bleed or cardiac puncture, was diluted and mixed in $200 \mu \mathrm{l} \mathrm{RPMI}$ containing $5 \mathrm{U} / \mathrm{ml}$ heparin sulphate. Diluted blood was stained simultaneously with Syto84 $(5 \mu \mathrm{M}$; Life Technologies) to detect RNA/DNA and Hoechst33342 $(10 \mu \mathrm{g} / \mathrm{ml}$; Sigma-Aldrich) to detect DNA for 30 minutes in the dark at room temper- 
ature. Staining was quenched with $2 \mathrm{ml} \mathrm{RPMI}$, and samples were immediately analyzed by flow cytometry using a BD FACSCanto II Analyzer (BD Biosciences) and FlowJo software (Treestar). prbc were readily detected as being Hoechst $33342^{+}$Syto $84^{+}$, with white blood cells excluded on the basis of size, granularity, and much higher Hoechst33342/Syto84 staining compared with prbc. Parasitemias were routinely measured at all day 4 p.i. analyses, with no statistically significant differences seen between PbA-infected WT C57BL/6 mice and those bearing any genetic modification.

Preparation of splenic lysates and detection of IFN- $\alpha$ protein and cytokines. Spleens were harvested into $2 \mathrm{ml}$ ice-cold RPMI containing a general protease inhibitor cocktail (P2714, Sigma-Aldrich; used according to the manufacturer's instructions) and passed through $100-\mu \mathrm{m}$ cell strainers to create single cell suspensions. $0.5 \% \mathrm{v} / \mathrm{v}$ Triton X-100 (Sigma-Aldrich) was added for 15 minutes on ice to lyse cells. Lysates were centrifuged at $14,000 \mathrm{~g}$ for 5 minutes to pellet cellular debris. Lysate supernatants were immediately snap frozen and stored at $-80^{\circ} \mathrm{C}$ until analyzed. IFN- $\alpha$ was detected in splenic lysates or sera using an antibody-based, cytometric bead kit (FlowCytomix, eBioscience), according to the manufacturer's instructions, with bead populations analyzed on a FACSArray analyzer and results processed using FCAP array software (BD Biosciences). All other cytokines were measured using CBA Flex Sets (BD Biosciences) according to the manufacturer's instructions, with samples assessed as above.

Flow cytometry and cell sorting. Blood and spleen mononuclear cells were prepared as previously described $(35,36,75)$, ensuring maximal recovery of splenic cDCs by treating spleens with deoxyribonuclease I $(0.5 \mathrm{mg} / \mathrm{ml}$; Worthington Biochemical) and collagenase type $4(1 \mathrm{mg} / \mathrm{ml}$; Worthington Biochemical) for 25 minutes at room temperature. Fluorescently conjugated mAbs against B220 (RA3-6B2), 120G8, CD11c-APC (N418), MHCII (M5/114.15.2), CD4 (GK1.5), CD8 $\alpha$ (53-6.7), IFN- $\gamma$ (XMG1.2), CD19 (6D5), CD45.1 (A20), CD45.2 (clone 104), Ly6C (HK1.4), CD11b (M1/70), CD40 (1C10), CD80 (16-10A1), CD86 (GL1), OX40L (RM134L), ICOSL (B7-RP1), and PDL2 (TY25) were purchased from Biolegend. Fluorescently conjugated mAbs against TCR $\beta$ chain (H57-597), NK1.1 (PK136), and PDL1 (MIH5) were purchased from BD Biosciences. AntiT-bet $\mathrm{mAb}$ (eBio4B10) was purchased from eBioscience, and anti-granzyme B (MHGB04) was purchased from Life Technologies. Cell surface and intracellular IFN- $\gamma$ staining was performed as previously described $(35,36)$.

To sort purify cDCs, pooled spleens were treated as above with deoxyribonuclease I and collagenase type 4, and rbc were lysed as previously described $(35,36,75)$. CD $11 \mathrm{ch}$ cells were enriched using CD11c microbeads according to the manufacturer's instructions (Miltenyi Biotec), and cDC subsets were identified during cell sorting as being (propidium iodide ${ }^{-} /$ TCR $\beta^{-} /$B $220^{-} / 1208^{-} /$CD $11 c^{\text {hi }}$ ) CD $11 b^{\text {lo-mid }}, C D 8 \alpha^{+/-}$(purity >99\%). Harvesting of $\mathrm{CDCs}$ from each group of mice within an experiment was staggered to minimize and normalize $\mathrm{cDC}$ isolation times for each group. Cells were recounted via Trypan Blue exclusion prior to plating.

In vivo receptor blockade, cell depletion, and poly I:C treatment. Anti-IFNAR1 blocking mAb (MAR1-5A3, Leinco Technologies Inc.) and its isotype control $\mathrm{mAb}$ were administered in $0.1 \mathrm{mg}$ doses, via i.p. injection, on the day of infection and 2 days afterward. Cellular depletion in langerin-DTR and Clec9a-DTR mice was performed by i.p. injection of $10 \mathrm{ng} / \mathrm{g}$ DT (Sigma-Aldrich) in $200 \mu \mathrm{l} 0.9 \%$ saline (Baxter) per mouse the day prior to infection and on days 1 and 3 p.i. poly I:C (Sigma-Aldrich) was dissolved in RPMI and administered as a single $100 \mu \mathrm{g}$ dose i.p on day 2 p.i.

$\mathrm{CD} 4^{+}$cell enrichment and adoptive transfer. Spleens from CD 45.1+ OTII mice were aseptically removed, and mononuclear cells were prepared as described previously $(35,75,79)$. CD $4{ }^{+}$cells were enriched using CD4 microbeads according to the manufacturer's instructions (Miltenyi Biotec) (CD4 ${ }^{+}$cell purity was routinely $85 \%$ ), labeled with CFSE $(5 \mu \mathrm{M}$; Life Technologies) in $\mathrm{Ca}^{2+} / \mathrm{Mg}^{2+}$-free $\mathrm{PBS}$ for 15 minutes at room temperature in the dark, and washed twice in 10 volumes $\mathrm{Ca}^{2+} / \mathrm{Mg}^{2+}$-free PBS. CFSE-labeled $\mathrm{CD}^{+}{ }^{+}$cells were resuspended in RPMI/2\% normal mouse serum, and $200 \mu \mathrm{l}$ volumes were injected i.v. via a lateral tail vein using a 26-gauge needle.

In vivo phagocytosis assay. This protocol was performed essentially as previously described $(16,17) .3 .64 \times 10^{10} 0.5 \mu \mathrm{m}$ Fluoresbrite Carboxylate Microspheres (Polysciences) were injected i.v. into mice, and, 3 hours later, spleens were harvested and processed as above.

Ex vivo $c D C$ priming of Th responses. $5 \times 10^{4}$ sort-purified cDCs (purity $>99 \%$ ) were plated in 96-well round-bottomed plates, with or without OTII peptide ( $40 \mathrm{ng} / \mathrm{ml}$ ) or E $\alpha 52-68$ peptide ( 40 or $400 \mathrm{ng} / \mathrm{ml}$ ), at a 1:1 ratio with $\mathrm{CD}^{+}$-enriched splenocytes from naive OTII mice or cell-sorted $\mathrm{CD} 4^{+} \mathrm{T}$ cells from the spleens of naive TEa mice. The culturing medium used was RPMI medium containing $5 \%(\mathrm{v} / \mathrm{v})$ fetal bovine serum, L-glutamine, penicillin $(100 \mathrm{U} / \mathrm{ml}) /$ streptomycin $(100 \mu \mathrm{g} / \mathrm{ml})$, sodium pyruvate $(2 \mathrm{mM}), \beta$-mercaptoethanol $(50 \mu \mathrm{M})$, and HEPES $(200 \mu \mathrm{M})$. After 72 hours of culturing at $37^{\circ} \mathrm{C} / 5 \% \mathrm{CO}_{2}$, tissue culture supernatants were assessed for cytokines using cytometric bead arrays, according to the manufacturer's instructions (BD Biosciences), with samples acquired on a purpose-built FACSArray Bioanalyzer (BD Biosciences). Wells were then pulsed with $1 \mathrm{mCi}[3 \mathrm{H}]$ thymidine for 18 hours, before measuring thymidine incorporation using a Betaplate Reader (Wallac). In addition, for TEa cells, intracellular T-bet staining was performed on individual replicate wells as above.

Quantitative PCR. RNA samples were quantitated using the Nanodrop ND-1000 (NanoDrop Technologies Inc.). RNA was reverse transcribed using the High-Capacity cDNA Reverse Transcription Kit (Applied Biosystems). Quantitative PCR was performed using TaqMan Gene Expression Probe Kits for genes encoding IFN- $\alpha 2$, IFN- $\alpha 4$, IFN- $\alpha 5$, IFN- $\alpha 6$, IFN- $\beta 1$, IL- 10 , and HPRT and TaqMan Gene Expression Master Mix (Applied Biosystems) on the Rotor Gene 6000 real-time rotary analyzer (Qiagen). Relative quantitation of gene expression was performed using the relative standard curve method, as described by Applied Biosystems. Briefly, standard curves were prepared for all target and endogenous control genes using cDNA from sort-purified CD8 ${ }^{-}$cDCs from Ifnar $1^{f / f l}$ mice 4 days p.i. HPRT was used as the endogenous control. The amount of target gene or endogenous control in each sample was calculated from the appropriate standard curves. The target amount was then divided by the endogenous control amount to give the normalized target value. Normalizes target values were compared with a calibrator sample, as outlined in the figure legends, to yield relative expression levels.

Statistics. Comparisons between 2 groups were performed using nonparametric Mann-Whitney tests or Student's $t$ tests for Gaussian distributions. $P<0.05$ was considered significant. Kruskal-Wallis tests were performed to analyze 3 groups within an experiment. Graphs depict mean \pm SEM, except when individual mouse data points are depicted, in which case median values are shown. All statistical analyses were performed using GraphPad Prism 5 or 6 software.

Study approval. Animal procedures were approved and monitored by the QIMR Berghofer Medical Research Institute Animal Ethics Committee (approval no. A02-633M) in accordance with Australian National Health and Medical Research Council guidelines. Clec9a-DTR mice were housed and used according to local animal ethics requirements at Nanyang Technological University.

\section{Acknowledgments}

We gratefully acknowledge the assistance of QIMR flow cytometry facility, animal facilities, and the audio-visual department. We thank Robert D. Schreiber (Washington University, St. Louis, Missouri, USA) for providing CD11c-Cre Ifnar $1^{f / f l}$ mice on a C57BL/6J background. We are grateful to William Heath (Melbourne University, Department of Microbiology and Immunology, Melbourne, Australia) for helpful discussions of this work. This work was 
principally funded by an Australian National Health and Medical Research Council Project grant (no. 1028641) to A. Haque and Program Grant funding (no. 1037304) to C.R. Engwerda. This work was also supported by a Singaporean National Medical Research Council grant, NMRC/1307/2011 to C. Ruedl, and by Singapore Immunology Network core grant from the Agency for Science, Technology and Research to L. Rénia.
Received for publication May 13, 2013, and accepted in revised form March 13, 2014.

Address correspondence to: Ashraful Haque, QIMR Berghofer Medical Research Institute, 300 Herston Road, Herston, QLD 4006, Australia. Phone: 61738453948; Fax: 61738453507; E-mail: Ashraful.haque@qimrberghofer.edu.au.
1. Auerbuch V, Brockstedt DG, Meyer-Morse N, O'Riordan M, Portnoy DA. Mice lacking the type I interferon receptor are resistant to Listeria monocytogenes. J Exp Med. 2004;200(4):527-533.

2. Carrero JA, Calderon B, Unanue ER. Type I interferon sensitizes lymphocytes to apoptosis and reduces resistance to Listeria infection. J Exp Med. 2004;200(4):535-540.

3. Stanley SA, Johndrow JE, Manzanillo P, Cox JS. The Type I IFN response to infection with Mycobacterium tuberculosis requires ESX-1-mediated secretion and contributes to pathogenesis. J Immunol. 2007;178(5):3143-3152.

4. Antonelli LR, et al. Intranasal Poly-IC treatment exacerbates tuberculosis in mice through the pulmonary recruitment of a pathogen-permissive monocyte/macrophage population. J Clin Invest. 2010; 120(5):1674-1682.

5. Berry MP, et al. An interferon-inducible neutrophildriven blood transcriptional signature in human tuberculosis. Nature. 2010;466(7309):973-977.

6. Desvignes L, Wolf AJ, Ernst JD. Dynamic roles of type I and type II IFNs in early infection with Mycobacterium tuberculosis. J Immunol. 2012; 188(12):6205-6215.

7. Teles RM, et al. Type I interferon suppresses type II interferon-triggered human anti-mycobacterial responses. Science. 2013;339(6126):1448-1453.

8. Parker D, Prince A. Staphylococcus aureus induces type I IFN signaling in dendritic cells via TLR9. J Immunol. 2012;189(8):4040-4046.

9. Teijaro JR, et al. Persistent LCMV infection is controlled by blockade of type I interferon signaling. Science. 2013;340(6129):207-211.

10. Wilson EB, et al. Blockade of chronic type I interferon signaling to control persistent LCMV infection. Science. 2013;340(6129):202-207.

11. Xin L, et al. Type I IFN receptor regulates neutrophil functions and innate immunity to Leishmania parasites. J Immunol. 2010;184(12):7047-7056.

12. Haque A, et al. Type I interferons suppress CD4 T-cell-dependent parasite control during bloodstage Plasmodium infection. Eur J Immunol. 2011; 41(9):2688-2698.

13. Sharma $S$, et al. Innate immune recognition of an AT-rich stem-loop DNA motif in the Plasmodium falciparum genome. Immunity. 2011;35(2):194-207.

14. Aucan C, et al. Interferon- $\alpha$ receptor-1 (IFNAR1) variants are associated with protection against cerebral malaria in the Gambia. Genes Immun. 2003; 4(4):275-282.

15. Khor CC, et al. Positive replication and linkage disequilibrium mapping of the chromosome $21 \mathrm{q} 22.1$ malaria susceptibility locus. Genes Immun. 2007; 8(7):570-576.

16. Lundie RJ, et al. Blood-stage Plasmodium berghei infection leads to short-lived parasite-associated antigen presentation by dendritic cells. Eur J Immunol. 2010;40(6):1674-1681.

17. Wilson NS, et al. Systemic activation of dendritic cells by Toll-like receptor ligands or malaria infection impairs cross-presentation and antiviral immunity. Nat Immunol. 2006;7(2):165-172.

18. Wykes MN, et al. Plasmodium strain determines dendritic cell function essential for survival from malaria. PLoS Pathog. 2007;3(7):e96.

19. Sponaas AM, et al. Malaria infection changes the ability of splenic dendritic cell populations to stimulate antigen-specific T cells. J Exp Med. 2006;203(6):1427-1433.

20. deWalick S, et al. Cutting edge: conventional dendritic cells are the critical APC required for the induction of experimental cerebral malaria. J Immunol. 2007;178(10):6033-6037.

21. Voisine C, Mastelic B, Sponaas AM, Langhorne J. Classical CD $11 \mathrm{c}^{+}$dendritic cells, not plasmacytoid dendritic cells, induce $\mathrm{T}$ cell responses to Plasmodium chabaudi malaria. Int J Parasitol. 2010; 40(6):711-719

22. Shortman K, Heath WR. The $\mathrm{CD}^{+}$dendritic cell subset. Immunol Rev. 2010;234(1):18-31.

23. Joffre OP, Segura E, Savina A, Amigorena S. Cross-presentation by dendritic cells. Nat Rev Immunol. 2012;12(8):557-569.

24. Dudziak D, et al. Differential antigen processing by dendritic cell subsets in vivo. Science. 2007; 315(5808):107-111.

25. Idoyaga J, et al. Comparable T helper 1 (Th1) and CD8 T-cell immunity by targeting HIV gag p 24 to CD8 dendritic cells within antibodies to Langerin, DEC205, and Clec9A. Proc Natl Acad Sci U S A. 2011;108(6):2384-2389.

26. Soares $\mathrm{H}$, et al. A subset of dendritic cells induces $\mathrm{CD}^{+} \mathrm{T}$ cells to produce IFN- $\gamma$ by an IL-12-independent but CD70-dependent mechanism in vivo. J Exp Med. 2007;204(5):1095-1106

27. Haque A, et al. Granzyme B expression by $\mathrm{CD}^{+} \mathrm{T}$ cells is required for the development of experimental cerebral malaria. JImmunol. 2011;186(11):6148-6156.

28. Schwandt T, et al. Expression of type I interferon by splenic macrophages suppresses adaptive immunity during sepsis. EMBO J. 2012;31(1):201-213.

29. Robb RJ, et al. Type I-IFNs control GVHD and GVL responses after transplantation. Blood. 2011; 118(12):3399-3409.

30. Jia T, Leiner I, Dorothee G, Brandl K, Pamer EG. MyD88 and type I interferon receptor-mediated chemokine induction and monocyte recruitment during Listeria monocytogenes infection. J Immunol. 2009;183(2):1271-1278

31. Lee PY, et al. Type I interferon modulates monocyte recruitment and maturation in chronic inflammation. Am J Pathol. 2009;175(5):2023-2033.

32. Belnoue E, et al. Chemokine receptor CCR2 is not essential for the development of experimental cerebral malaria. Infect Immun. 2003;71(6):3648-3651.

33. Cervantes-Barragan L, et al. Type I IFN-mediated protection of macrophages and dendritic cells secures control of murine coronavirus infection. J Immunol. 2009;182(2):1099-1106.

34. Cucak H, Yrlid U, Reizis B, Kalinke U, Johansson-Lindbom B. Type I interferon signaling in dendritic cells stimulates the development of lymph-node-resident $\mathrm{T}$ follicular helper cells. Immunity. 2009;31(3):491-501.

35. Amante FH, et al. Immune-mediated mechanisms of parasite tissue sequestration during experimental cerebral malaria. J Immunol. 2010;185(6):3632-3642.

36 . Haque $\mathrm{A}$, et al. $\mathrm{CD}^{+}$natural regulatory $\mathrm{T}$ cells prevent experimental cerebral malaria via CTLA-4 when expanded in vivo. PLoS Pathog. 2010;6(12):e1001221.

37. Lundie RJ, et al. Blood-stage Plasmodium infection induces $\mathrm{CD}^{+} \mathrm{T}$ lymphocytes to parasite-expressed antigens, largely regulated by $\mathrm{CD} 8 \alpha^{+}$dendritic cells. Proc Natl Acad Sci U S A. 2008;105(38):14509-14514.

38. Kissenpfennig A, et al. Dynamics and function of
Langerhans cells in vivo: dermal dendritic cells colonize lymph node areas distinct from slower migrating Langerhans cells. Immunity. 2005;22(5):643-654.

39. Piva L, Tetlak P, Claser C, Karjalainen K, Renia L, Ruedl C. Cutting edge: Clec9A ${ }^{+}$dendritic cells mediate the development of experimental cerebral malaria. J Immunol. 2012;189(3):1128-1132.

40. Tubo NJ, et al. Single naive $\mathrm{CD}^{+} \mathrm{T}$ cells from a diverse repertoire produce different effector cell types during infection. Cell. 2013;153(4):785-796.

41. Koyama M, et al. Recipient nonhematopoietic antigen-presenting cells are sufficient to induce lethal acute graft-versus-host disease. Nat Med. 2012;18(1):135-142.

42. Guermonprez P, et al. Inflammatory Flt3l is essential to mobilize dendritic cells and for $\mathrm{T}$ cell responses during Plasmodium infection. Nat Med. 2013;19(6):730-738.

43. Khoury DS, et al. Effect of mature blood-stage Plasmodium parasite sequestration on pathogen biomass in mathematical and in vivo models of malaria. Infect Immun. 2014;82(1):212-220.

44. Wykes MN, Liu XQ, Jiang S, Hirunpetcharat C, Good MF. Systemic tumor necrosis factor generated during lethal Plasmodium infections impairs dendritic cell function. J Immunol. 2007;179(6):3982-3987.

45. Elliott SR, et al. Inhibition of dendritic cell maturation by malaria is dose dependent and does not require Plasmodium falciparum erythrocyte membrane protein 1. Infect Immun. 2007;75(7):3621-3632.

46. Ocana-Morgner C, Mota MM, Rodriguez A. Malaria blood stage suppression of liver stage immunity by dendritic cells. J Exp Med. 2003; 197(2):143-151.

47. Urban BC, et al. Plasmodium falciparum-infected erythrocytes modulate the maturation of dendritic cells. Nature. 1999;400(6739):73-77.

48. Saito Y, et al. Regulation by SIRP $\alpha$ of dendritic cell homeostasis in lymphoid tissues. Blood. 2010; 116(18):3517-3525

49. Li LX, Atif SM, Schmiel SE, Lee SJ, McSorley SJ. Increased susceptibility to Salmonella infection in signal regulatory protein $\alpha$-deficient mice. J Immunol. 2012;189(5):2537-2544.

50. Fortin G, et al. A role for CD47 in the development of experimental colitis mediated by SIRP $\alpha^{+} \mathrm{CD} 103^{-}$ dendritic cells. J Exp Med. 2009;206(9):1995-2011.

51. Sponaas AM, et al. Migrating monocytes recruited to the spleen play an important role in control of blood stage malaria. Blood. 2009;114(27):5522-5531.

52. Leon B, Lopez-Bravo M, Ardavin C. Monocyte-derived dendritic cells formed at the infection site control the induction of protective $T$ helper 1 responses against Leishmania. Immunity. 2007;26(4):519-531.

53. Serbina NV, Salazar-Mather TP, Biron CA, Kuziel WA, Pamer EG. TNF/iNOS-producing dendritic cells mediate innate immune defense against bacterial infection. Immunity. 2003;19(1):59-70.

54. Gilliet M, Cao W, Liu YJ. Plasmacytoid dendritic cells: sensing nucleic acids in viral infection and autoimmune diseases. Nat Rev Immunol. 2008;8(8):594-606.

55. Kim CC, Nelson CS, Wilson EB, Hou B, DeFranco AL, DeRisi JL. Splenic red pulp macrophages produce type I interferons as early sentinels of malaria infection but are dispensable for control. PLoS One. 2012;7(10):e48126.

56. Stockinger S, et al. Characterization of the interferon-producing cell in mice infected with Listeria 
monocytogenes. PLoS Pathog. 2009;5(3):e1000355.

57. Trottein F, et al. A type I IFN-dependent pathway induced by Schistosoma mansoni eggs in mouse myeloid dendritic cells generates an inflammatory signature. J Immunol. 2004;172(5):3011-3017.

58. Manzotti CN, Liu MK, Burke F, Dussably L, Zheng Y, Sansom DM. Integration of CD28 and CTLA4 function results in differential responses of T cells to CD80 and CD86. Eur J Immunol. 2006; 36(6):1413-1422.

59. Sansom DM, Manzotti CN, Zheng Y. What's the difference between CD80 and CD86? Trends Immunol. 2003;24(6):314-319.

60. Zheng Y, Manzotti CN, Liu M, Burke F, Mead KI, Sansom DM. CD86 and CD80 differentially modulate the suppressive function of human regulatory T cells. J Immunol. 2004;172(5):2778-2784.

61. Butler NS, et al. Therapeutic blockade of PD-L1 and LAG-3 rapidly clears established blood-stage Plasmodium infection. Nat Immunol. 2012;13(2):188-195.

62. Hafalla JC, et al. The CTLA-4 and PD-1/PD-L1 inhibitory pathways independently regulate host resistance to Plasmodium-induced acute immune pathology. PLoS Pathog. 2012;8(2):e1002504.

63. Ghiotto M, et al. PD-L1 and PD-L2 differ in their molecular mechanisms of interaction with PD-1. Int Immunol. 2010;22(8):651-660.

64. Axtell RC, et al. T helper type 1 and 17 cells determine efficacy of interferon- $\beta$ in multiple sclerosis and experimental encephalomyelitis. Nat Med. 2010;16(4):406-412.

65. Axtell RC, Raman C, Steinman L. Type I interferons: beneficial in Th1 and detrimental in Th17 autoimmunity. Clin Rev Allergy Immunol. 2013;44(2):114-120.

66. Agnandji ST, et al. A phase 3 trial of RTS,S/AS01 malaria vaccine in African infants. $N$ Engl J Med. 2012;367(24):2284-2295.

67. Good MF, Xu H, Wykes M, Engwerda CR. Development and regulation of cell-mediated immune responses to the blood stages of malaria: implications for vaccine research. Annu Rev Immunol. 2005; 23:69-99.

68. Johnson MJ, et al. Type I IFN induced by adenovirus serotypes 28 and 35 has multiple effects on T cell immunogenicity. JImmunol. 2012;188(12):6109-6118.

69. Schuldt NJ, Amalfitano A. Malaria vaccines: focus on adenovirus based vectors. Vaccine. 2012; 30(35):5191-5198.

70. Hwang SY, et al. A null mutation in the gene encoding a type I interferon receptor component eliminates antiproliferative and antiviral responses to interferons $\alpha$ and $\beta$ and alters macrophage responses. Proc Natl Acad Sci US A. 1995;92(24):11284-11288.

71. Swann JB, et al. Type I IFN contributes to NK cell homeostasis, activation, and antitumor function. J Immunol. 2007;178(12):7540-7549.

72. Kamphuis E, Junt T, Waibler Z, Forster R, Kalinke U. Type I interferons directly regulate lymphocyte recirculation and cause transient blood lymphopenia. Blood. 2006;108(10):3253-3261.

73. Boring L, et al. Impaired monocyte migration and reduced type 1 (Th1) cytokine responses in C-C chemokine receptor 2 knockout mice. J Clin Invest. 1997;100(10):2552-2561.

74. Hogquist KA, Jameson SC, Heath WR, Howard JL, Bevan MJ, Carbone FR. T cell receptor antagonist peptides induce positive selection. Cell. 1994; 76(1):17-27.

75. Amante $\mathrm{FH}$, et al. A role for natural regulatory $\mathrm{T}$ cells in the pathogenesis of experimental cerebral malaria. Am J Pathol. 2007;171(2):548-559.

76. Apte SH, Groves PL, Roddick JS, da Hora VP, Doolan DL. High-throughput multi-parameter flow-cytometric analysis from micro-quantities of plasmodium-infected blood. Int J Parasitol. 2011;41(12):1285-1294.

77. Klonis N, et al. Artemisinin activity against Plasmodium falciparum requires hemoglobin uptake and digestion. Proc Natl Acad Sci U S A. 2011; 108(28):11405-11410.

78. Malleret B, et al. A rapid and robust tri-color flow cytometry assay for monitoring malaria parasite development. Sci Rep. 2011;1:118.

79. Haque A, et al. Therapeutic glucocorticoid-induced TNF receptor-mediated amplification of $\mathrm{CD}^{+} \mathrm{T}$ cell responses enhances antiparasitic immunity. JImmunol. 2010;184(5):2583-2592. 